\title{
A rotary-shear low to high-velocity friction apparatus in Beijing to study rock friction at plate to seismic slip rates
}

\author{
Shengli Ma - Toshihiko Shimamoto • \\ Lu Yao • Tetsuhiro Togo • Hiroko Kitajima
}

Received: 18 July 2014/ Accepted: 25 August 2014/Published online: 30 September 2014

(c) The Seismological Society of China, Institute of Geophysics, China Earthquake Administration and Springer-Verlag Berlin Heidelberg 2014

\begin{abstract}
This paper reviews 19 apparatuses having highvelocity capabilities, describes a rotary-shear low to highvelocity friction apparatus installed at Institute of Geology, China Earthquake Administration, and reports results from velocity-jump tests on Pingxi fault gouge to illustrate technical problems in conducting velocity-stepping tests at high velocities. The apparatus is capable of producing plate to seismic velocities (44 mm/a to $2.1 \mathrm{~m} / \mathrm{s}$ for specimens of $40 \mathrm{~mm}$ in diameter), using a $22 \mathrm{~kW}$ servomotor with a gear/belt system having three velocity ranges. A speed range can be changed by $10^{3}$ or $10^{6}$ by using five electromagnetic clutches without stopping the motor. Two cam clutches allow fivefold velocity steps, and the motor speed can be increased from zero to $1,500 \mathrm{rpm}$ in $0.1-0.2 \mathrm{~s}$ by changing the controlling voltage. A unique feature of the apparatus is a large specimen chamber where different specimen assemblies can be installed easily. In addition to a standard specimen assembly for friction experiments, two pressure vessels were made for pore pressures to $70 \mathrm{MPa}$; one at room temperature and the other at temperatures to
\end{abstract}

S. Ma $(\bowtie) \cdot$ T. Shimamoto $\cdot$ L. Yao · T. Togo

State Key Laboratory of Earthquake Dynamics,

Institute of Geology, China Earthquake Administration,

Beijing 100029, China

e-mail: masl@ies.ac.cn

Present Address:

T. Togo $\cdot$ H. Kitajima

Institute of Earthquake and Volcano Geology, Advanced Institute for Industrial Science and Technology (AIST), Tsukuba

Central 7, 1-1-1 Higashi, Tsukuba, Ibaraki 305-8567, Japan

H. Kitajima

Department of Geology and Geophysics, Center for

Tectonophysics, Texas A\&M University, College Station,

TX 77843, USA
$500{ }^{\circ} \mathrm{C}$. Velocity step tests are needed to see if the framework of rate-and-state friction is applicable or not at high velocities. We report results from velocity jump tests from $1.4 \mathrm{~mm} / \mathrm{s}$ to $1.4 \mathrm{~m} / \mathrm{s}$ on yellowish gouge from a Pingxi fault zone, located at the northeastern part of the Longmenshan fault system that caused the 2008 Wenchuan earthquake. An instantaneous increase in friction followed by dramatic slip weakening was observed for the yellowish gouge with smooth sliding surfaces of host rock, but no instantaneous response was recognized for the same gouge with roughened sliding surfaces. Instantaneous and transient frictional properties upon velocity steps cannot be separated easily at high velocities, and technical improvements for velocity step tests are suggested.

Keywords Low to high-velocity friction apparatus . High-velocity friction - Velocity-jump test .

Longmenshan fault system · Pingxi fault

\section{Introduction}

High-velocity friction experiments on rocks started from the frictional melting experiments by Spray (1987, 1988, 1993, 1995, 2005) using orbital, radial, and axial frictional welding machines. He successfully reproduced textural and chemical characteristics of pseudotachylites (Spray 2010; references therein), but the shear stress along a simulated fault was not be reported. A rotary-shear high-velocity friction apparatus built by Shimamoto and Tsutsumi (1994) produced seismic slip rates (up to $1.3 \mathrm{~m} / \mathrm{s}$ ) while measuring shear stress. Studies with this and several other apparatuses (Tsutsumi and Shimamoto 1997a; Goldsby and Tullis 2002; Di Toro et al. 2006, 2010; Fukuyama and Mizoguchi 2010; Reches and Lockner 2010; Tsutsumi et al. 2011; 


\section{High-Velocity Frictional Testing Apparatuses}

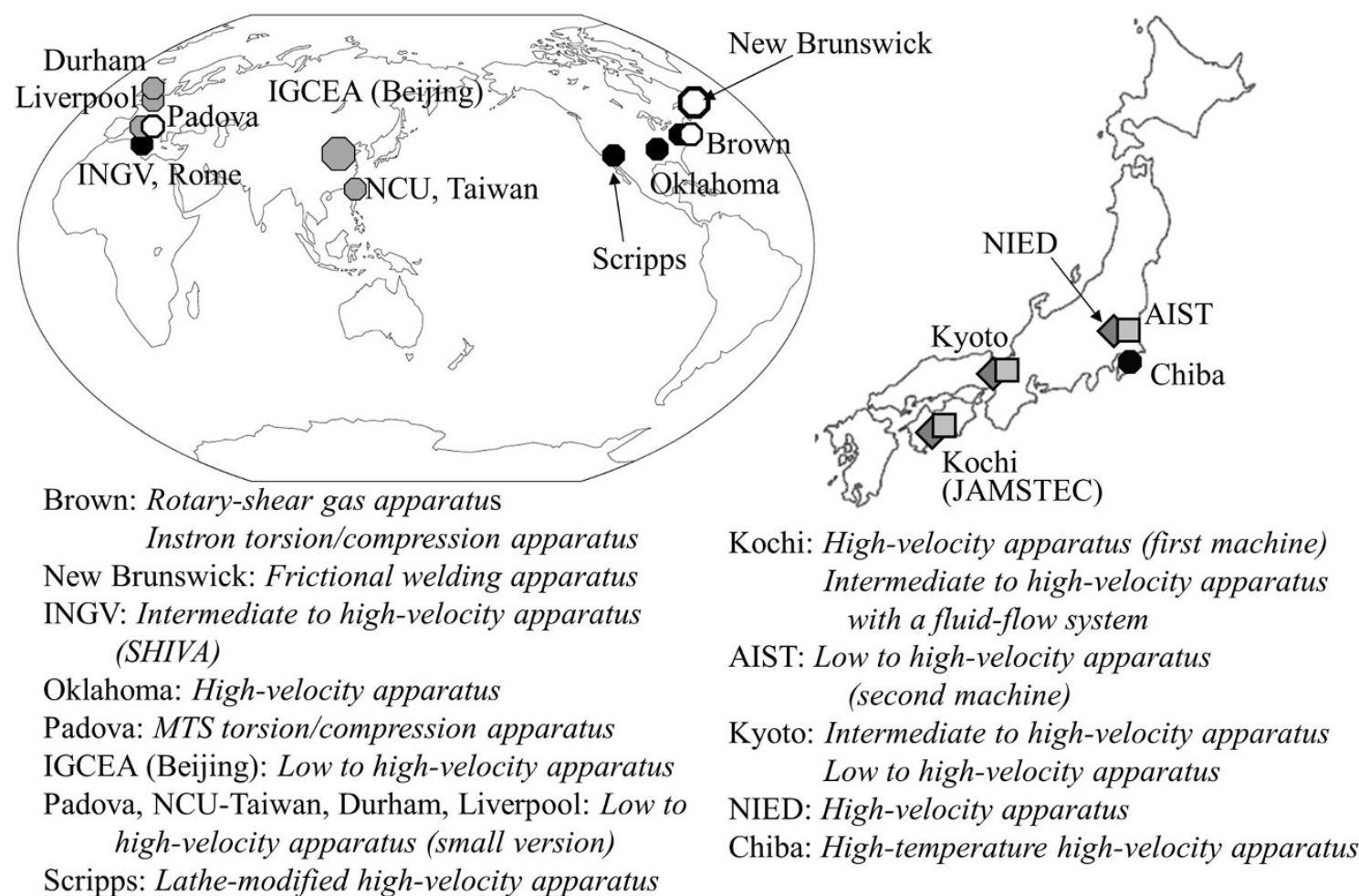

Fig. 1 Rotary-shear friction apparatuses with high-velocity capabilities and locations of the institutions (see Table 1 for a list of apparatuses with their capabilities)

Tanikawa et al. 2012) have demonstrated dramatic weakening of faults at slip rates of about $0.001 \sim 1 \mathrm{~m} / \mathrm{s}$ due to different mechanisms (e.g., Di Toro et al. 2011). Highvelocity friction of faults has become an important subject in fault and earthquake mechanics, and there are nineteen friction apparatuses with high-velocity capability in the world now (Fig. 1). We outline those apparatuses and give a brief summary of main research outcomes in the next section (see a summary of capabilities of apparatuses in Table 1).

Despite numerous studies in the last two decades, the majority of experiments were done at low normal-stress and room humidity conditions although some experiments were done at $\sigma_{\mathrm{n}}$ to $26 \mathrm{MPa}$ or with controlled pore pressures to $15 \mathrm{MPa}$ (e.g., Smith et al. 2013; Violay et al. 2013, 2014). Obvious improvements to friction apparatuses are along three lines; (1) to expand the velocity capability to extremely low slip rate to study the frictional properties associated with nucleation to dynamic rupture propagation during large earthquakes, (2) to include controlled pore pressure at room to high temperatures (hydrothermal conditions) to simulate realistic conditions in fault zones at depths, and (3) to expand the normal-stress capability to the order of $100 \mathrm{MPa}$ to reproduce seismic fault motion at great depths. Lockner and Reches called an apparatus with such capabilities "dream machine" at "TAMU Friction Machine Workshop" held at Texas A\&M University on Feb. 13-17, 2012. Shimamoto and Hirose built a rotaryshear low to high-velocity friction apparatus in 1997 (Shimamoto and Hirose 2006; see Togo and Shimamoto 2012 for details of the apparatus). This apparatus, often called the second high-velocity machine, was designed to meet the requirements (1) and (2), and has a capability of producing slip rates from $3 \mathrm{~mm} / \mathrm{a}$ to almost $10 \mathrm{~m} / \mathrm{s}$. It would be necessary to conduct friction experiments with supercritical water to determine frictional properties relevant to slow-slip and low-frequency tremors in subduction zones (e.g., Obara 2002; Shelly 2009). Thus, a hydrothermal pressure vessel was built for the apparatus, but it has become clear that developing a general-purpose pressure vessel to achieve diverse conditions is not an easy task.

We report here another rotary-shear low to high-velocity friction apparatus (Marui Co. Ltd., Osaka, Japan, MIS-2331-76) installed at Institute of Geology, China Earthquake Administration (IGCEA) in October 2010, which may be called the third high-velocity friction apparatus. The concept of building this apparatus was the same as the second apparatus, i.e., to meet the requirements (1) and (2) above. 


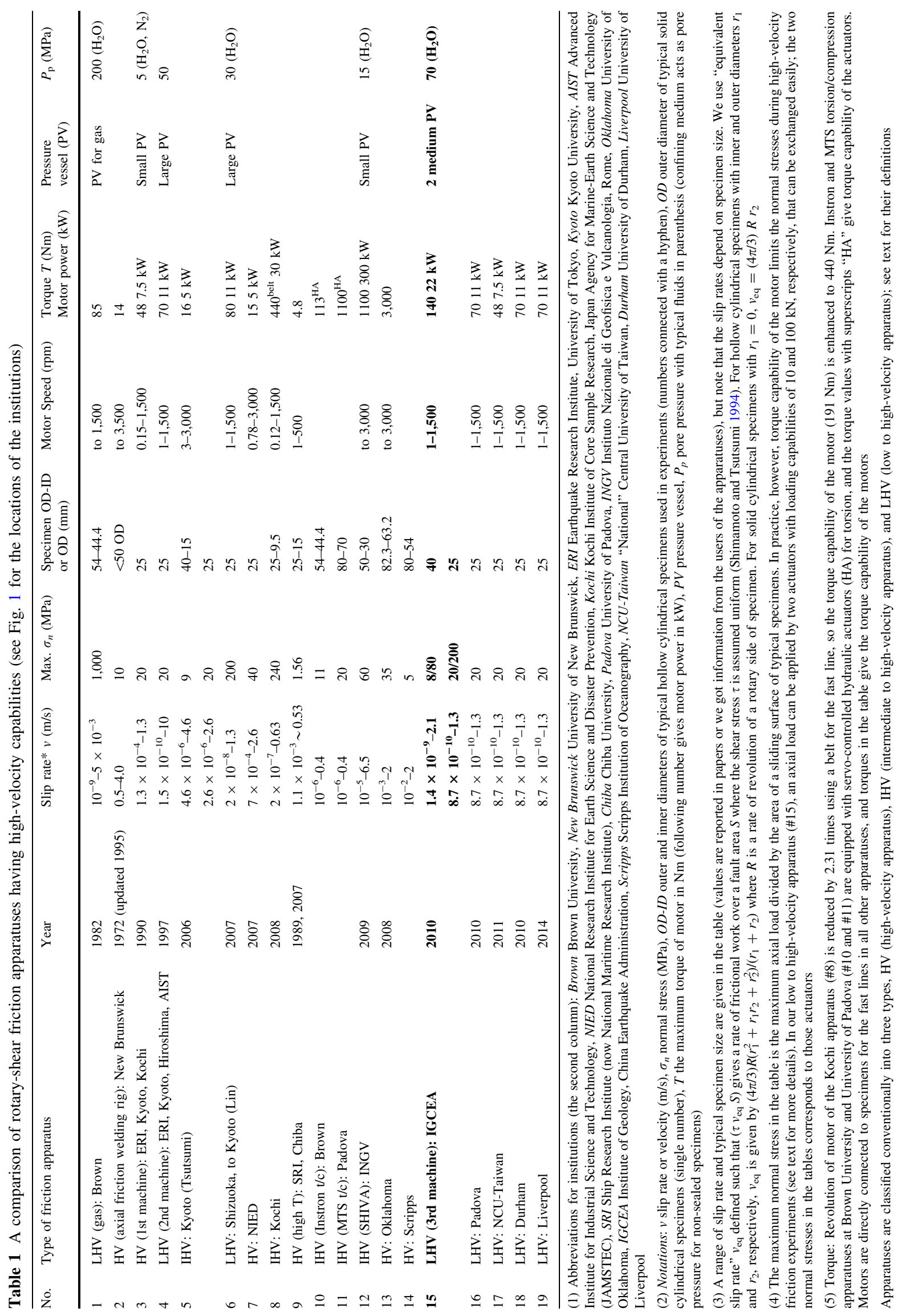


However, the most important modification was to make a fairly large specimen chamber where workers can build a variety of specimen assemblies, including a hydrothermal pressure vessel, and easily set one up to the apparatus, thereby increasing feasibility of the apparatus to different problems without modifications to the apparatus itself. The motor power was increased to $22 \mathrm{~kW}$ to produce a torque to $140 \mathrm{~N} \mathrm{~m}$ (about twice as large as that of the second machine), but increasing a normal stress to the order of $100 \mathrm{MPa}$ is not intended with this apparatus. Smaller versions of the apparatuses with very similar designs were installed at University of Padova, "National" Central University of Taiwan, Durham University, and recently to University of Liverpool.

After descriptions of the apparatus, this paper will report preliminary results on Shanxi dolerite at controlled pore pressure using the first pressure vessel for this apparatus. We just built a hydrothermal pressure vessel with an external furnace that could produce water pressure to $70 \mathrm{MPa}$ at temperatures to $470{ }^{\circ} \mathrm{C}$ in preliminary tests, but this vessel will be reported elsewhere. This paper also report results from velocity jump tests by 1,000 times (from $1.4 \mathrm{~mm} / \mathrm{s}$ to $1.4 \mathrm{~m} / \mathrm{s}$ ), conducted on the yellowish gouge from the Pingxi fault zone, located near the northeastern end of the coseismic faults that moved during the 2008 Wenchuan earthquake. Yao et al. (2013a, b) and Chen et al. (2013a) report internal structures of this fault zone and results from high-velocity friction experiments conducted with our IGCEA apparatus, and we will not report the structures of this fault zone here. Velocity step tests are quite useful to separate the instantaneous and transient responses upon a step change in slip rate that are a basis for establishing rate-and-state frictional constitutive laws (Dieterich 1978, 1979; Ruina 1983). However, velocity step tests at high velocities are not easy, and we are not aware of successful work on this so far. Our velocity jump tests illustrate subtle nature of frictional responses to a step change in velocity at high velocities, and we discuss technical difficulties and possible improvements of the apparatus for velocity step tests at high velocities.

\section{Rotary-shear friction apparatuses with high-velocity capabilities}

\subsection{Classification of friction apparatuses}

Figure 1 gives locations of the institutions that own nineteen rotary-shear high-velocity friction apparatuses that have been used in the high-velocity friction studies, and Table 1 lists their capabilities. A disadvantage of rotaryshear apparatus is a large gradient in slip rate; i.e., zero in the center and the maximum at the periphery of a solid cylindrical specimen. We use "equivalent slip rate" $v_{\mathrm{eq}}$ as a slip rate or velocity here as in most papers quoted below [see caption (3) of Table 1]. Shear stress $\tau$ is converted from measured torque assuming a uniform shear stress $\tau$ although this assumption is unlikely to be valid at high velocities. With this assumption, however, only $12.5 \%$ of torque is due to the friction on the inner half of the cylindrical specimen, so that rotary-shear friction experiments are insensitive to the friction on the inner part of specimens. Because of this, experiments with solid and hollow cylindrical specimens often exhibit similar results. We briefly review rotary-shear friction apparatuses and main research outcomes below and outline motivations for building our low to high-velocity friction apparatus at IGCEA described in the next section. We restricted our review to the rotary-shear apparatuses used in the studies of fault mechanics, and did not cover impact high-velocity apparatuses (e.g., Yuan and Prakash 2008) and rotary-shear apparatuses in engineering such as large-scale rotary-shear apparatuses developed by Sassa et al. (2007; references therein) to study earthquake-induced landslides.

We first define conventional terminology of velocity ranges to describe friction apparatuses in the next subsection because more than ten apparatuses in Table 1 have a capability to produce low to intermediate slip rates, in addition to high velocities. Friction experiments were done at low slip rates of $(0.3-3) \times 10^{-9} \mathrm{~m} / \mathrm{s}$ or $32-95 \mathrm{~mm} / \mathrm{a}$ (Kawamoto and Shimamoto 1997; Blanpied et al. 1987; Shimamoto 1986) to a velocity as high as $6.5 \mathrm{~m} / \mathrm{s}$ (Niemeijer et al. 2011). Future experiments will cover even slower slip rates to study frictional properties related to earthquake nucleation, and indeed a biaxial friction apparatus can produce a slip rate as low as $3 \times 10^{-12} \mathrm{~m} / \mathrm{s}$ or $0.1 \mathrm{~mm} / \mathrm{a}$ (Kawamoto and Shimamoto 1997). In view of those possible velocity ranges in laboratory friction experiments, we conventionally use $10^{-7}$ and $10^{-4} \mathrm{~m} / \mathrm{s}$ as the boundary between low and intermediate velocities and that between intermediate and high velocities, respectively. With this definition, friction apparatuses with high-velocity capabilities can be classified as follows, using the minimum and the maximum velocities, $v_{\min }$ and $v_{\max }$ :

HV (high-velocity apparatus): $v_{\min } \geq 10^{-4} \mathrm{~m} / \mathrm{s}$,

IHV (intermediate to high-velocity apparatus): $10^{-4} \mathrm{~m} / \mathrm{s}>v_{\min } \geq 10^{-7} \mathrm{~m} / \mathrm{s}$, and $v_{\max } \geq 10^{-4} \mathrm{~m} / \mathrm{s}$, and LHV (low to high-velocity apparatus): $v_{\min }<10^{-7} \mathrm{~m} / \mathrm{s}$, and $v_{\max } \geq 10^{-4} \mathrm{~m} / \mathrm{s}$.

The abbreviations are used in column 2 of Table 1 . Note that the velocity ranges were defined to describe friction apparatuses, not to describe frictional properties. Slip rates of $10^{-6}$ and $10^{-3} \mathrm{~m} / \mathrm{s}$ could have been used as the boundaries. However, rotary-shear apparatuses with direct connection between a specimens and a motor can produce 
slip rates of around $10^{-4} \mathrm{~m} / \mathrm{s}$ by using a servomotor. As a classification of testing machines, it is desirable to classify those apparatuses as high-velocity (HV) apparatuses and $10^{-4} \mathrm{~m} / \mathrm{s}$ is appropriate to do so. Likewise, apparatuses with one gear/belt system can produce slip rates close to $10^{-7} \mathrm{~m} / \mathrm{s}$ and hence a slip rate of $10^{-7} \mathrm{~m} / \mathrm{s}$ is appropriate to classify them as intermediate to high-velocity (IHV) apparatuses. Low to high-velocity (LHV) apparatuses are normally equipped with more than two gear/belt systems to reduce slip rates by two to three orders of magnitudes by reducing one gear/belt line.

Some rocks begin to show marked slip weakening at slip rates greater than about $10^{-4} \mathrm{~m} / \mathrm{s}$ (Di Toro et al. 2004, 2011), so that $10^{-4} \mathrm{~m} / \mathrm{s}$ may be a good boundary mechanically as well. Moreover, the velocity dependence of the steady-state friction changes from velocity weakening to velocity strengthening with increasing slip rate at slip rates of $10^{-6}$ $10^{-5} \mathrm{~m} / \mathrm{s}$ for halite shear zones (Shimamoto 1986) and at $10^{-5}-10^{-4} \mathrm{~m} / \mathrm{s}$ for granite (Blanpied et al. 1987). Thus, such a change in velocity dependence could occur within the intermediate velocities. Rate \& state frictional properties (e.g., Dieterich 1979; Ruina 1983) have been determined at slip rates lower than the above change in the velocity dependence. Low-velocity friction apparatuses should have wide enough velocity ranges in the low-velocity regime to determine the rate and state frictional properties.

\subsection{Friction apparatuses and research outcomes}

Our review here is organized with friction apparatuses, not with respect to the subjects of high-velocity friction studies. Table 1 gives a list of capabilities of the apparatuses and we describe only characteristic features of the apparatuses in our review below. Before a seismic slip rate on the order of $1 \mathrm{~m} / \mathrm{s}$ was achieved in laboratory friction experiments on rocks, T. E. Tullis had built a sophisticated rotary-shear triaxial gas apparatus at Brown University in 1982 to conduct friction experiments on hollow cylindrical specimens of $55 \mathrm{~mm}$ in outer diameter at the very wide slip rates ranging $10^{-9}-5 \times 10^{-3} \mathrm{~m} / \mathrm{s}(32 \mathrm{~mm} / \mathrm{a}$ to $5 \mathrm{~mm} / \mathrm{s})$ (\#1 in Table 1; Tullis and Weeks 1986; Blanpied et al. 1987; Beeler et al. 1996; Goldsby and Tullis 2002). Although the seismic slip rate could not be achieved, normal stresses up to about $1 \mathrm{GPa}$ could be applied with this apparatus and the rate of frictional work could be almost as high as that achieved with the high-velocity friction apparatus operated at very low normal stresses. An important finding was that dramatic slip-weakening could occur at subseismic slip rates where frictional heating is not important, possibly due to the formation of gel-like materials along the simulated faults (Goldsby and Tullis 2002).

Spray (1987, 1988, 1993, 1995, 2005) conducted frictional melting experiments using three types of frictional welding machines, developed in the engineering industries since the 1950s, and successfully reproduced natural pseudotachylites (see Spray 2010 for a summary of his work). The first experiments were done on dry metadolerite with an orbital welding machine at a normal stress of 4.2 MPa (Spray 1987). Two cylindrical specimens were rotated at very high speed $(3,000 \mathrm{rpm})$ in the same direction with their axes offset by $1.5 \mathrm{~mm}$, and the mean surface velocity was $0.24 \mathrm{~m} / \mathrm{s}$ which was high enough to produce frictional melting. Spray (1988) also performed frictional melting experiments on amphibolite with a radial frictional welding machine by rotating a steel ring compressed from outside against a cylindrical rock specimen in a steel casing, at a revolution rate of $750 \mathrm{rpm}$. After those exploratory experiments, Spray (1993, 1995, 2005) conducted very detailed frictional melting experiments on granite and other rocks, using a continuous drive axial frictional welding apparatus, now at New Brunswick (\#2 in Table 1), which is capable of producing slip rates of $0.5-4.0 \mathrm{~m} / \mathrm{s}$ at normal stresses to $10 \mathrm{MPa}$ (applied with an air actuator), using a set of cylindrical specimens less than $50 \mathrm{~mm}$ in outer diameter.

A rotary-shear high-velocity (HV) friction apparatus built by Shimamoto and Tsutsumi (1994) at Earthquake Research Institute, University of Tokyo, is probably the first apparatus used in fault mechanics that produced seismic slip rates ( $v$ to $1.3 \mathrm{~m} / \mathrm{s}$ ) while measuring shear stress (\#3 in Table 1). The apparatus was used initially in frictional melting experiments (Tsutsumi and Shimamoto 1996, 1997a, b; Lin and Shimamoto 1998; Tsutsumi 1999), and it was moved to Kyoto University and then to Kochi Institute of Core Sample Research (JAMSTEC). During those periods, the apparatus was fully used to study a wide variety of problems associated with seismic fault motion; that is, the frictional melting in more detail (Hirose and Shimamoto 2005; Di Toro et al. 2006; Nielsen et al. 2008; Del Gaudio et al. 2009; Ujiie et al. 2009), dramatic weakening of various fault gouges at seismic slip rates (Mizoguchi et al. 2007, 2009a; Sone and Shimamoto 2009; Tanikawa and Shimamoto 2009; Kitajima et al. 2010, 2011), mineral decompositions due to frictional heating and thermochemical pressurization (Han et al. 2007a, b; Hirose and Bystricky 2007; Brantut et al. 2008), formation of clay-clast aggregates (Boutareaud et al. 2010), wet gouge experiments (Faulkner et al. 2011), mylonitic deformation in the brittle fields associated with seismic fault motion (Kim et al. 2010; Ree et al. 2014), wear of rocks during frictional sliding (Hirose et al. 2012), rapid healing of friction following seismic slip (Mizoguchi et al. 2009b), coal gasification (O'Hara et al. 2006), changes in ESR signal and vitrinite maturation during seismic slip (Fukuchi et al. 2005; Kitamura et al. 2012), resetting of the $\mathrm{K}-\mathrm{Ar}$ age during frictional melting (Sato et al. 2009), $\mathrm{H}_{2}$ 
generation during seismogenic fault motion that can sustain subsurface biosphere (Hirose et al. 2011), catastrophic landslide (Ferri et al. 2010, 2011), and frictional melting and high-velocity frictional properties of volcanic rocks (Lavallée et al. 2012, 2014; Kendrick et al. 2014).

The importance of high-velocity friction of faults was recognized through early studies to promote building of LHV friction apparatuses (Fig. 1). Shimamoto and Hirose built a rotary-shear LHV friction apparatus in 1997 at Earthquake Research Institute, University of Tokyo, and it was moved to Kyoto University, to Hiroshima University, and then to Advanced Industrial Science and Technology (AIST) in Tsukuba, Japan (\#4 in Table 1; Shimamoto and Hirose 2006; see Togo and Shimamoto 2012 for details of the apparatus). This apparatus is often called the second high-velocity machine, but its slip rate capability covers a very wide range, $10^{-10} \mathrm{~m} / \mathrm{s}$ (about $3 \mathrm{~mm} / \mathrm{a}$ ) to almost $10 \mathrm{~m} / \mathrm{s}$, and normal stresses to about $20 \mathrm{MPa}$ for cylindrical specimens of $25 \mathrm{~mm}$ in outer diameter. It was used for gouge experiments (De Paola et al. 2011; Togo et al. 2011), shear-induced graphitization and graphite behaviors (Oohashi et al. 2011, 2013), energetics of gouge deformation (Togo and Shimamoto 2012; Sawai et al. 2012), temperature suppression due to dehydration (Brantut et al. 2011), possible powder lubrication (Han et al. 2010, 2011), and initiation processes of an earthquake-induced landslide (Togo et al. 2014).

Several rotary-shear friction apparatuses were built in Japan since then. A. Tsutsumi built an IHV friction apparatus at Kyoto University with capabilities of $v=5 \mu \mathrm{m} / \mathrm{s}$ to $4.6 \mathrm{~m} / \mathrm{s}$ and normal stress $\sigma_{\mathrm{n}}$ to $20 \mathrm{MPa}$ for specimens of 40 and $15 \mathrm{~mm}$ in outer and inner diameters, respectively (\#5 in Table 1). The apparatus was used for studying the behavior of gouge from accretionary prism (Tsutsumi et al. 2011; Ujiie and Tsutsumi 2010; Ujiie et al. 2011; Saito et al. 2013; Namiki et al. 2014), hydrated amorphous silica formation along a fault in chert (Hayashi and Tsutsumi 2010), and J-FAST drill core in Japan trench (Ujiie et al. 2013). A. Lin installed a LHV apparatus with two specimen assemblies including one with a pressure vessel at Shizuoka University (now moved to Kyoto University; $v=0.6 \mathrm{~m} / \mathrm{a}$ to $1.3 \mathrm{~m} / \mathrm{s}, \sigma_{\mathrm{n}}$ to $200 \mathrm{MPa}$ for specimens of $25 \mathrm{~mm}$ in outer diameter), and applied it to dehydration and melting of serpentinite at seismic slip rates (\#6 in Table 1; Lin et al. 2013). Fukuyama and Mizoguchi built a compact HV apparatus at National Institute for Earth Science and Disaster Prevention (NIED) with $v=0.7 \mathrm{~mm} / \mathrm{s}$ to $2.6 \mathrm{~m} / \mathrm{s}, \sigma_{\mathrm{n}}$ to $40 \mathrm{MPa}$, and a good accelerating capability of $107 \mathrm{~m} / \mathrm{s}^{2}$ to produce variable slip histories (\#7 in Table 1). They used it to reproduce a realistic seismic fault motion expressed by a regularized Yoffe function (Fukuyama and Mizoguchi 2010) and to study weakening and wear of gabbroic rocks at subseismic slip rates
(Mizoguchi and Fukuyama 2010). Tanikawa and Hirose at Kochi Institute of Core Sample Research (JAMSTEC) built a powerful IHV apparatus equipped with a pressure cell and fluid-flow system for permeability measurements during frictional sliding (\#8 in Table $1 ; v=0.2 \mu \mathrm{m} / \mathrm{s}$ to $0.6 \mathrm{~m} / \mathrm{s}, \sigma_{\mathrm{n}}$ to $240 \mathrm{MPa}$ for specimens of 25 and $9.5 \mathrm{~mm}$ in the outer and inner diameters, respectively; see Tanikawa et al. 2010, 2012, 2014). A unique apparatus is a hightemperature rotary-shear apparatus at Chiba University which was recently applied to friction experiments on dolerite at temperatures to $1,000{ }^{\circ} \mathrm{C}$ by Noda et al. (2011). It was built in 1989 by Senda to study friction and wear of ceramics at high temperatures (e.g., Senda et al. 1995) and is equipped with a very powerful high-frequency induction heater to increase temperature to $1,000{ }^{\circ} \mathrm{C}$ with a heating rate up to $120^{\circ} \mathrm{C} / \mathrm{min}$ in an atmospheric controlling chamber (\#9 in Table $1 ; v=1.1 \mathrm{~mm} / \mathrm{s}$ to $0.53 \mathrm{~m} / \mathrm{s}$ and $\sigma_{\mathrm{n}}$ to $1.56 \mathrm{MPa}$ for specimens of 25 and $15 \mathrm{~mm}$ in outer and inner diameters, respectively). Senda kindly offered the apparatus to Kanagawa to be used in the earth science community.

An Instron servo-hydraulically controlled torsion/compression IHV apparatus at Brown University (\#10 in Table 1) was used in important work on rock friction by $\mathrm{Di}$ Toro et al. (2004) on dramatic weakening of fault in novaculite due to silica gel formation, and by Goldsby and Tullis (2011) and Kohli et al. (2011) on flash weakening of crustal rocks and serpentinite, respectively. The apparatus was used in those papers at $v=1 \mu \mathrm{m} / \mathrm{s}$ to $0.4 \mathrm{~m} / \mathrm{s}$ and $\sigma_{\mathrm{n}}$ to $11 \mathrm{MPa}$ for hollow cylindrical specimens with outer and inner diameters of 54 and $44.4 \mathrm{~mm}$, respectively. The torsional hydraulic actuator allows forward and backward motion over an angle of about $90^{\circ}$, but not the continuous revolution of the loading column. A similar apparatus, MTS 809 at University of Padova (\#11 in Table 1; $v=1 \mu \mathrm{m} / \mathrm{s}$ to $0.4 \mathrm{~m} / \mathrm{s}$ and $\sigma_{\mathrm{n}}$ to $20 \mathrm{MPa}$ ) was used for studying low-velocity of friction of landslide material (Ferri et al. 2011) and flash weakening of fault in limestone (Tisato et al. 2012).

A slow to high-velocity apparatus (SHIVA) was built by Di Toro, Nielsen, and others at Instituto Nazionale di Geofisica e Vulcanologia (INGV), Rome, in 2009 with capabilities of $v=10 \mu \mathrm{m} / \mathrm{s}$ to $6.5 \mathrm{~m} / \mathrm{s}$ and $\sigma_{\mathrm{n}}$ to $60 \mathrm{MPa}$ (\#12 in Table 1; Di Toro et al. 2010; this apparatus is classified as an IHV apparatus). At present, this is one of the most powerful apparatuses with a torque and acceleration capabilities of $1,100 \mathrm{~N} \mathrm{~m}$ and $80 \mathrm{~m} / \mathrm{s}^{2}$, respectively, and has begun to produce flood of papers; Niemeijer et al. (2011) on frictional melting, Smith et al. (2013) and Fondriest et al. (2013) on local dynamic recrystallization and fault mirror, respectively, as geological evidences of seismic fault motion, Violay et al. $(2013,2014)$ on the effect of controlled pore water pressure on the marked weakening of 
marble and microgabbro at seismic slip rates, and Kuo et al. (2014) on the graphitization of amorphous carbon in fault gouge during seismic fault motion. Another ambitious HV apparatus was built by Reches and Lockner at University of Oklahoma with a capability of $v=0.001-1 \mathrm{~m} / \mathrm{s}$ and $\sigma_{\mathrm{n}}$ to $35 \mathrm{MPa}$ (\#13 in Table 1), and it was used in the high-velocity experiments on granite by Reches and Lockner (2010) and on the development of nanoscale smooth surface in dolomite and its role on friction by Chen et al. (2013b). A unique feature of the apparatus is a heavy rotary plate called "spinning flywheel" whose kinetic energy can be controlled by simply changing the rate of revolution. Chang et al. (2012) used this to impose different levels of energy to a fault and produced earthquakelike fault motion with a similar scaling with those for natural earthquakes. A simple lathe-modified $\mathrm{HV}$ friction apparatus with capabilities of $v=0.01-2.0 \mathrm{~m} / \mathrm{s}$ and $\sigma_{\mathrm{n}}$ to $5 \mathrm{MPa}$ (\#14 in Table 1) was built at Scripps Institution of Oceanography by Brown and Fialko (2012) who reported high-velocity weakening and strengthening of gabbro, somewhat similar to those reported in Hirose and Shimamoto (2005).

Our LHV friction apparatus at IGCEA is compared with other apparatuses (\#15 in Table 1), and next subsection explains how the specifications of this apparatus were selected. Smaller versions of friction apparatuses with a very similar design were installed at University of Padova, "National" Central University of Taiwan, University of Durham, and University of Liverpool (\#16-\#19 in Table 1). Our apparatus was applied to the high-velocity friction experiments on fault gouge from the Longmenshan fault system that caused the 2008 Wenchuan earthquake (Hou et al. 2012; Yao et al. 2013a, b; Chen et al. 2013a, c). Balsimo et al. (2014) used the Durham apparatus in the friction experiments on poorly lithified fault zones for better understanding of the mechanisms of earthquakes along shallow creeping faults.

\subsection{A scope for building our LHV friction apparatus}

Most high-velocity friction experiments cited above were done at low normal stresses, typically less than several $\mathrm{MPa}$, and achieving high-normal stress conditions is essential in reproducing seismic fault motion at depths in laboratory experiments. The 5th column of Table 1 gives values of the maximum axial force divided by the fault area (normal stress capability) of the apparatuses. In practice, however, the normal stress, that can be applied during high-velocity friction experiments, is limited (1) by the strength of specimens and (2) by the torque capability of motor or a hydraulic torsional actuator. The uniaxial strengths of rocks during high-velocity friction experiments reduce by two to three orders of magnitudes due to thermal fracturing (Ohtomo and Shimamoto 1994), and this is one of the main reasons why most high-velocity friction experiments were done at normal stresses below several $\mathrm{MPa}$. Use of a metal sleeve outside of rock specimens can increase the normal stress to a few tens of MPa (e.g., Di Toro et al. 2006). Metal specimen holders are convenient to apply high normal stresses (e.g., Smith et al. 2013; Balsimo et al. 2014), but care must be taken in interpreting the results because of the differences in thermal conductivity between rocks and metals. Rocks exhibit marked weakening at slip rates of $10^{-4}-10^{-2} \mathrm{~m} / \mathrm{s}$ (e.g., Di Toro et al. 2011), whereas metals begin to show weakening at a slip rate of around $1 \mathrm{~m} / \mathrm{s}$ (Lim et al. 1989). The difference in thermal conductivity between the two is the most likely cause for this difference because the temperature increase due to frictional heating is suppressed in thermally conductive metals. We address this issue in a separate paper.

Another problem is the motor power which is often limited by a power line available in a laboratory. Assuming a uniform shear stress $\tau$ over the sliding surface, torque $T$ is given by:

$T=(\pi \tau / 12)\left(R_{\mathrm{o}}^{3}-R_{\mathrm{i}}^{3}\right)=\left(\pi \mu \sigma_{\mathrm{n}} / 12\right)\left(R_{\mathrm{o}}^{3}-R_{\mathrm{i}}^{3}\right)$,

where $R_{\mathrm{o}}$ and $R_{\mathrm{i}}$ are outer and inner diameters, respectively, $\mu$ is a friction coefficient, and $\sigma_{\mathrm{n}}$ is a normal stress. For a given torque of a motor (8th column of Table 1 ), the maximum normal stress for high-velocity friction experiments can be calculated from this equation. We selected a moderate size of a servomotor with a power of $22 \mathrm{~kW}$ and a torque capability of $140 \mathrm{Nm}$, and actuators of 10 and $100 \mathrm{kN}$ in loading capabilities for our apparatus. The actuators can be exchanged easily and allow normal stresses of 8 or $80 \mathrm{MPa}$ for solid cylindrical specimens of $40 \mathrm{~mm}$ in diameter, and of 20 or $200 \mathrm{MPa}$ for specimens of $25 \mathrm{~mm}$ in diameter (\#15 in Table 1). With direct connection between the motor and specimens with $\mu=0.8$, the limits of normal stresses from Eq. (1) for conducting highvelocity experiments are 10 and $43 \mathrm{MPa}$ for specimens of 40 and $25 \mathrm{~mm}$ in diameters, respectively. Use of smaller specimens of $15 \mathrm{~mm}$ in diameter reduces the maximum slip rate to $0.8 \mathrm{~m} / \mathrm{s}$; the high-velocity experiments can be done at $\sigma_{\mathrm{n}}$ to $200 \mathrm{MPa}$. Thus, the motor power would be enough to solve technical problems for conducting highvelocity friction experiments at very high normal stresses. The $100 \mathrm{kN}$ actuator is useful at intermediate and low velocities because of much higher torque capabilities, thanks to the gear/belt systems.

We considered that extending experimental conditions to hydrothermal conditions is the most serious challenge in designing our apparatus because natural faults zones at depths are likely at moderate to high temperatures under fluid-rich environments and because most high-velocity experiments reviewed above have been done under dry 
with room humidity conditions. Building a hydrothermal pressure vessel with an external furnace was challenged in the second machine (\#4 in Table 1), but the water volume in the vessel was too large to conduct high-velocity experiments safely. Shimamoto realized through this experience that building hydrothermal pressure vessel for high-velocity experiments is not easy and that different specimen assemblies and pressure vessels are needed for different purposes. A natural strategy that had come out from this experience was to build an apparatus with a common platform for specimen assembly where a variety of specimen assemblies with or without a pressure vessel can be built and mounted very easily. This has become the most important strategy for building our apparatus at IGCEA.

As for the slip rate capability, we selected a gear/belt system to cover slow, intermediate, and high velocities because frictional properties change at the three regimes, and the changes are important for full understanding of the nucleation to dynamic rupture processes of earthquakes. The minimum slip rate for the second machine was $10^{-10}$ $\mathrm{mm} / \mathrm{s}(3 \mathrm{~mm} / \mathrm{a}$; \#4 in Table 1$)$. We thought that this minimum rate is too slow in practice to conduct experiments, and we selected a plate velocity of the order of $10^{-9} \mathrm{~mm} / \mathrm{s}$ as the minimum rate for our apparatus. In both apparatuses, all slip rates (ten or nine orders of magnitude) can be achieved seamlessly by changing the motor speed and gear/ belt lines. A new attempt with our apparatus was to use cam clutches for producing five-times velocity changes mechanically to separate instantaneous and transient responses of friction upon a step change in slip rate.

LHV friction apparatuses at Padova, NCU-Taiwan, Durham and Liverpool are of the same design as our apparatus except that they are equipped with smaller motors and do not have cam clutches (\#16-19 in Table 1). There are six HV apparatuses, five IHV apparatuses, and eight LHV apparatuses operational at present (Table 1). One HV and seven LHV apparatuses were designed by Shimamoto (TS).

\section{Rotary-shear LHV friction apparatus in Beijing}

\subsection{Constitution of the apparatus}

The apparatus is $3.2 \mathrm{~m}$ tall (Fig. 2) and consists of (1) a $22 \mathrm{~kW}$ AC servomotor with a torque capability to $140 \mathrm{~N} \mathrm{~m}$ (1 in Fig. 2b; Yaskawa, SGMBH-2BACA6S), (2) a gear/ belt system for three ranges of slip rates, (3) a steel loading frame, (4) a rotary encoder (Omron, E6C3-5GH) to monitor the revolution rate and cumulative revolutions, and a potentiometer (Midori Precisions, CPP-60) to detect a rotation angle, (5) solid or hollow cylindrical specimens, (6) specimen holders, (7) an aluminum specimen box to hold the stationary side of specimen holder, (8) an axial loading column, (9) a cantilever-type torque gauge, (10) an axial displacement transducer (strain-gauge type; Tokyo Sokki Kenkyujo, CDP-10S2), (11) a thrust bearing to support the axial load for nearly free rotation of the loading column, (12) an axial force gauge (Tokyo Sokki Kenkyujo, CLG-100KNB), and (13) an air actuator to apply an axial force to $10 \mathrm{kN}$ (Fujikura Composites, Bellofram Cylinder FCS-140-122-S1-R). The air actuator can be replaced with a servo-controlled hydraulic actuator to apply an axial force to $100 \mathrm{kN}$ (a servo-system is being installed now).

The most unique part of this apparatus is the specimen chamber in the center that is $697 \mathrm{~mm}$ high, $570 \mathrm{~mm}$ wide, and $550 \mathrm{~mm}$ deep. There are rotary column and axial loading column, both of $40 \mathrm{~mm}$ in diameters, at the top and bottom of the chamber that are separated by $482 \mathrm{~mm}$. Any specimen assembly shorter than this gap can be mounted by connecting the upper and lower pistons from the specimen assembly to those columns. We use ETP hub-shaft connections of Miki Pully not only for connecting the pistons with rotary and axial loading columns, but also for holding specimens in standard specimen holder without a pressure vessel (6 in Fig. 2b). This connecting device is a cylindrical flat jack to be inserted between an inner hole and a shaft which can be tightened simply by rotating a screw to increase the inner pressure in the flat jack. A ball bush at the top of the aluminum specimen holds the stationary side of the specimen and allows its easy axial motion. The center of the rotary specimen has to be adjusted to coincide with the center of rotation of the rotating column within a few microns to prevent off-centered rotation. We use a Teflon sleeve outside the specimen (see Appendix in Sawai et al. 2012), and the stationary specimen has to be positioned within a few to several microns to the rotary specimen to prevent the loss of gouge. The ETP connections are convenient for the fine adjustments because the position of inner shaft or specimen can be adjusted by a few microns by hitting it with a plastic hammer just before fully tightening the connection. A specimen assembly with a pressure vessel will be described later.

Figure $3 \mathrm{a}$ and $\mathrm{b}$ show photographs of the left side of the cantilever-type torque gauge which consists horizontal arms of $250 \mathrm{~mm}$ long and of an axial force gauge on the left side (1 kN; Tokyo Sokki Kenkyujo, CLA-1KNA), respectively. The central plate of the torque gauge is connected to the 

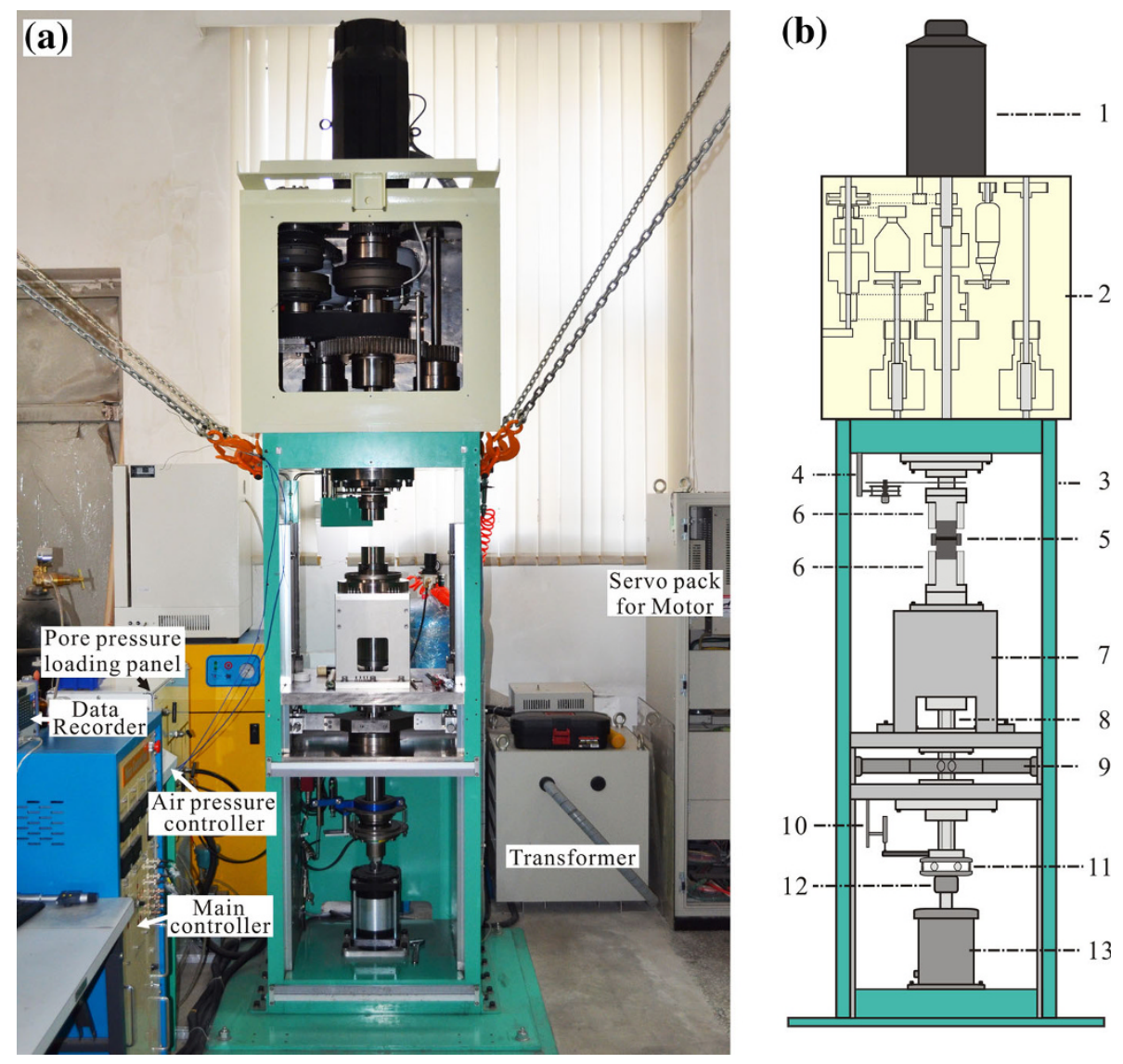

Fig. 2 a A photograph of the rotary-shear low to high-velocity frictional testing machine (LHVR-Beijing) at Institute of Geology, China Earthquake Administration. b A schematic diagram of the main units of the apparatus. 1 servo-motor, 2 gear/belt system for speed change, 3 loading frame, 4 rotary encoder, 5 specimen assembly, 6 locking devices of specimens, 7 frame for holding the lower loading column, 8 axial loading column, 9 torque gauge, 10 axial displacement transducer, 11 thrust bearing, 12 axial force gauge, 13 air actuator

axial loading column through a ball spline that allows the axial movement of the column without changing the position of the torque gauge. The axial force is supported by a thrust bearing with low friction (11 in Figs. 2b, 3a) so that nearly all torque is supported by the torque gauge. An averaged output from the two strain-gauge-based force gauges on both sides is used as an output from the torque gauge. A calibration of the torque gauge was done using several weights pulling the arm $(0.375 \mathrm{~m}$ from the center of the loading column) attached to the torque-gauge plate (Fig. 3a) to get a calibration results in Fig. 3c. There is a very good linear relationship between the torque and the output with a correlation coefficient $R^{2}=0.99996$, and the calibration covers the torque limit of the servomotor $(140 \mathrm{~N} \mathrm{~m})$. To make sure that the thrust bearing is not supporting a large torque, we measured the torque gauge output $T$ under a pair of weights $(30.219 \mathrm{~kg}$ in total) during an increase in the axial force $F$ from 0 to $8 \mathrm{kN}$, and then an decrease in $F$ back to zero (Fig. 3d). The changes in the output during the loading (blue circles) and unloading (small red circles) are fit with the following equations (blue and red lines):

$$
\begin{aligned}
T= & (111.06 \pm 0.02) \\
& +\left(3.37 \times 10^{-5} \pm 4.37 \times 10^{-6}\right) F(\text { loading }) \\
T= & (110.33 \pm 0.02) \\
& +\left(1.43 \times 10^{-4} \pm 4.67 \times 0^{-6}\right) F(\text { unloading }),
\end{aligned}
$$

where the errors are standard errors in the least-squares fitting with the Origin software. We used a small dish bearing with a diameter $r_{\mathrm{d}}$ of $12 \mathrm{~mm}$ between the upper and lower steel specimens in the calibration, so that the friction of this bearing and that of the thrust bearing with a diameter $r_{\mathrm{t}}$ of $40 \mathrm{~mm}$ can support a torque during the calibration. Assuming that the friction coefficient $\mu_{\mathrm{bb}}$ is the same for both bearings and that the axial force dependence is determined by the friction of the bearings, the slope of the $T$ versus $F$ relationship is given $\mu_{\mathrm{bb}}\left(r_{\mathrm{t}}+r_{\mathrm{d}}\right)$ and the two slopes for the loading and unloading give $\mu_{\mathrm{bb}}$ of 0.00065 and 0.0028 (0.0017 on the average), respectively. This friction coefficient is not unreasonable for ball bearings. However, we do not know exactly what caused the difference in the calibration curves in Fig. 3d, but the axial- 

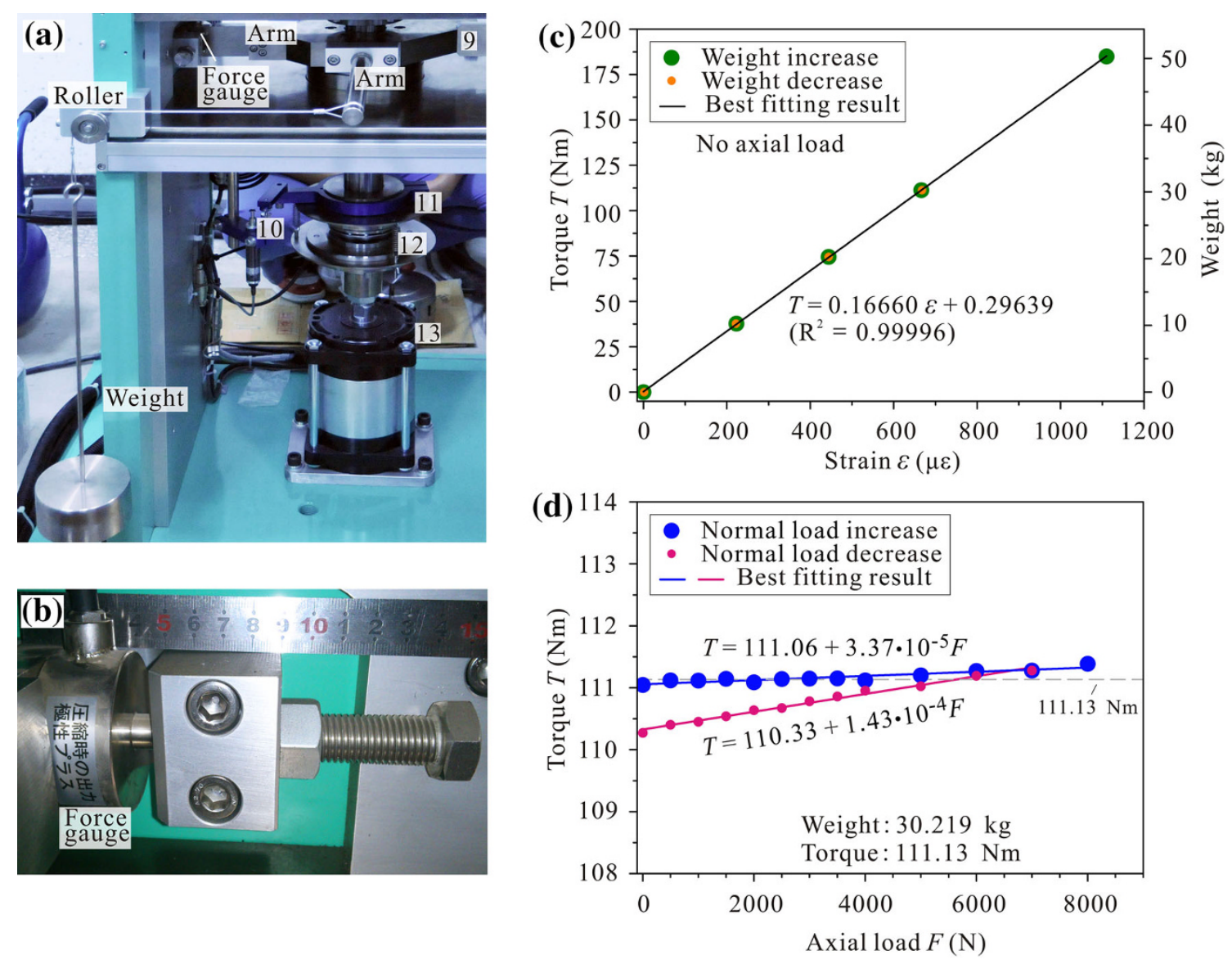

Fig. 3 a, b Photographs showing the left half of the torque gauge during its calibration and a compressional force gauge used in the torque gauge, respectively, $\mathbf{c}$ a calibration record for the torque gauge without an axial load $F$ by applying four different torques $T$ (left vertical axis) with different weights (right vertical axis), and $\mathbf{d}$ a record of the torque-gauge calibration during an axial-force cycling under a constant weight of $30.219 \mathrm{~kg}$. Numbers for parts in a are the same as those in the previous figure. The output from the torque gauge is given by a strain $\varepsilon$ in a unit of $\mu \varepsilon\left(10^{-6}\right)$ in $\mathbf{c}$, and $R^{2}$ is the determination coefficient in the least-squares fitting. Weight values given in $\mathbf{c}$ and $\mathbf{d}$ are sums of the two metal weights used in the front and back sides during the calibration

loading cycle probably twisted the torque gauge slightly differently during the loading and unloading. The circumference of the dish bearing is $23 \%$ of that of the thrust bearing, so that about one-fifth of the extra torque measured in the calibration is due to the dish bearing which we do not have in friction experiments.

A problem that became clear in the calibrations is a variation in the torque gauge outputs for $F=0$ (Fig. 3d). The total weight of $30.219 \mathrm{~kg}$ in the calibration gives a torque of $111.13 \mathrm{~N} \mathrm{~m}$ (a horizontal-dashed line in Fig. 3d), and the torque calibration in Fig. $3 \mathrm{c}$ was done using the torque values as calculated by the weight multiplied by the arm length. But the torque values determined from the outputs of the torque gauge using the calibration vary from 111.06 to $110.33 \mathrm{~N} \mathrm{~m}$ (intercepts of the fit lines in Fig. 3d). Therefore, the torque gauge output varies by $0.7 \%$ of the imposed torque. Two strain-gauge-based axial compressional force gauges are used in our torque gauge (see one of them in Fig. 3b); i.e., a torque exerted on the arms of the torque gauge pushes those compressional force gauges to measure the torque. The force gauges are compressional force gauges, not compression/torsion force gauges, and hence we had to impose small forces to the force gauges by tightening bolts (see a bolt on the right side of Fig. 3b) to fix the force gauges and the arms to prevent free rotary movement of the arm to the negative direction of torque. The force gauges are so sensitive that their outputs are affected by slight changes in the contact conditions between the arms and the force gauges. Fluctuations in the torque gauge outputs and different behaviors during loading and unloading are probably caused by the axial ball spline and the frictional junctions at the force gauge contacts, and those can cause an error in the measuring absolute torque values by almost $1 \%$. However, the torque 
gauge outputs are very stable under a given condition (Fig. 3d), and much smaller changes in torque should be detectable under a fixed condition. Use of compression/ tension force gauges may improve the torque gauge in the future.

A cantilever-type torque gauge is thus quite sensitive, but its disadvantage is a low characteristic frequency of about $200 \mathrm{~Hz}$ because the heavy loading column cannot be accelerated easily and because the arms of the torque gauge reduce their stiffness. We tried to move the torque gauge very close to the specimen, but the specimen holder of the stationary specimen became too unstable to conduct highvelocity friction experiments. Making a quick-response torque gauge with a high characteristic frequency is still left for a future task, and this poses a serious technical problem in conduction velocity step tests as we discuss in detail later.

An axial force up to $10 \mathrm{kN}$ is applied with a Bellofram cylinder at the bottom (13 in Fig. 2b) which operates with a compressed air pressure to $0.7 \mathrm{MPa}$. A large stroke of the cylinder $(122 \mathrm{~mm})$ allows flexible setting of various specimen assemblies to the specimen chamber. No seal is used for moving parts in the cylinder, and it can react to a change in air pressure as low as $0.01 \mathrm{MPa}$. A level of axial load is controlled with a Fairchild model 10 pneumatic precision regulator. The regulator is precise and easy to use, but it is slow to react to the change in air pressure, and the axial force during high-velocity friction experiments fluctuates typically by about 2-3\%. We plan to replace the Bellofram cylinder with a servo-controlled hydraulic actuator to $100 \mathrm{kN}$ very soon to extend the axial load capability by 10 times.

An axial displacement is monitored in all experiments, but the displacement transducer is not close to the specimens. Therefore, we need a transducer measuring the change in specimen lengths accurately. The rate of revolution (or slip rate) and cumulative revolutions (or displacement) are monitored by using a tachometer and a pulse counter (Coco Research, TDP-3921 and CNT-3921), respectively. The Omron encoder gives 3,600 pulses of signals per revolution which gives a resolution of $0.1^{\circ}$ or a displacement of $2.3 \times 10^{-5} \mathrm{~m}$ or $23 \mu \mathrm{m}$ for a solid cylindrical specimen of $40 \mathrm{~mm}$ in diameter. More accurate measurements of displacement are done with a potentiometer which gives an output of $10 \mathrm{~V}$ per revolution, but the output is reset for a rotation of $355^{\circ}$ and we use the output at low to intermediate velocities. We record outputs from torque gauge, axial force gauge, axial displacement transducer, rotary encoder, and potentiometer in Kyowa Universal Recorder EDX-100A with a sampling frequency up to $10 \mathrm{kHz}$ for 8 channels. We record data mostly with $1 \mathrm{kHz}$ sampling rate and analyze them following the procedures described in Yao et al. (2013a).
3.2 Gear-belt system for producing low to intermediate velocities

Our gear/belt system (Fig. 4a) is designed to produce three ranges of speed with a fast line $\left(1.4 \times 10^{-3}-2.1 \mathrm{~m} / \mathrm{s}\right)$, an intermediate line $\left(1.4 \times 10^{-6}-2.1 \times 10^{-3} \mathrm{~m} / \mathrm{s}\right)$, and a slow line $\left(1.4 \times 10^{-9}-2.1 \times 10^{-6} \mathrm{~m} / \mathrm{s}\right)$. The fast line is a direct line from a servomotor (Yaskawa, SGMBH2BACA6S) to the specimen (line $A$ in the center of Fig. 4a). The range of slip rate above corresponds to a range of revolution rate $(1-1,500 \mathrm{rpm})$ of the motor (the speed can be reduced more by nearly one order of magnitude with the motor). A speed in the intermediate line is reduced by 1,000 times by using belts, gear box GB1, and gears on lines $B$ and $C$, and the speed in the slow line drops by another 1,000 times with gears and gear box GB2 on lines $D$ and $E$ in Fig. 4a. Note that the ranges of slip rates decrease by three orders of magnitudes from the fast to intermediate lines and from the intermediate to slow lines. Thus, a speed change by more than nine orders of magnitude is achieved by changing motor speed and gear/belt arrangements. The system became compact by using two gear boxes, GB1 and GB2 (Nissei Corporation, G3L-28200-040 and G3L-32-375-020) which have speed reductions of 200 and 375 times and torque capabilities of 431 and $391 \mathrm{~N} \mathrm{~m}$, respectively.

Gear/belt lines can be changed without stopping the motor, by using five electromagnetic clutches MC1-MC5 [Ogura Clutches, MC1: MSC-40T (a torque limit of $400 \mathrm{~N} \mathrm{~m})$, MC2: MSC-10T (100 Nm), MC3 and MC3: MSC-70T (700 Nm), and MC5: MSC-20T (200 N m)]. The use of electromagnetic clutches was attempted in a gear system of a biaxial friction apparatus (Kawamoto and Shimamoto 1997; Noda and Shimamoto 2009) and in the second machine (Togo and Shimamoto 2012). A basic idea is to let all gears and belts connected and select an active line by turning on and off of electromagnetic clutches by a switch, without stopping the motor, allowing safe and quick changes in the gear/belt lines. Belts are used in fast moving parts to avoid noises coming from gears. In our gear/belt system, the fast line is active when MC1 is connected and all other clutches are disconnected (a gear or a pully of a belt is disconnected from the column in the center when the clutch is off). To change the fast line to the intermediate line, turn off MC1 and turn on MC2 and MC3 all simultaneously by an electric switch, then the rotation of the motor is transmitted to line $B$ by a belt hidden behind a plate on the upper-left corner of Fig. 4a, to GB1 on line $C$ by a thin belt on the upper-left corner, and back to the main line $A$ through a big final gear in the center to reduce the rate of revolution by 1,000 times. To go down to the slow line, turn off MC3 to disconnect the final big gear from line $C$ and turn on MC4 to activate the slow line 


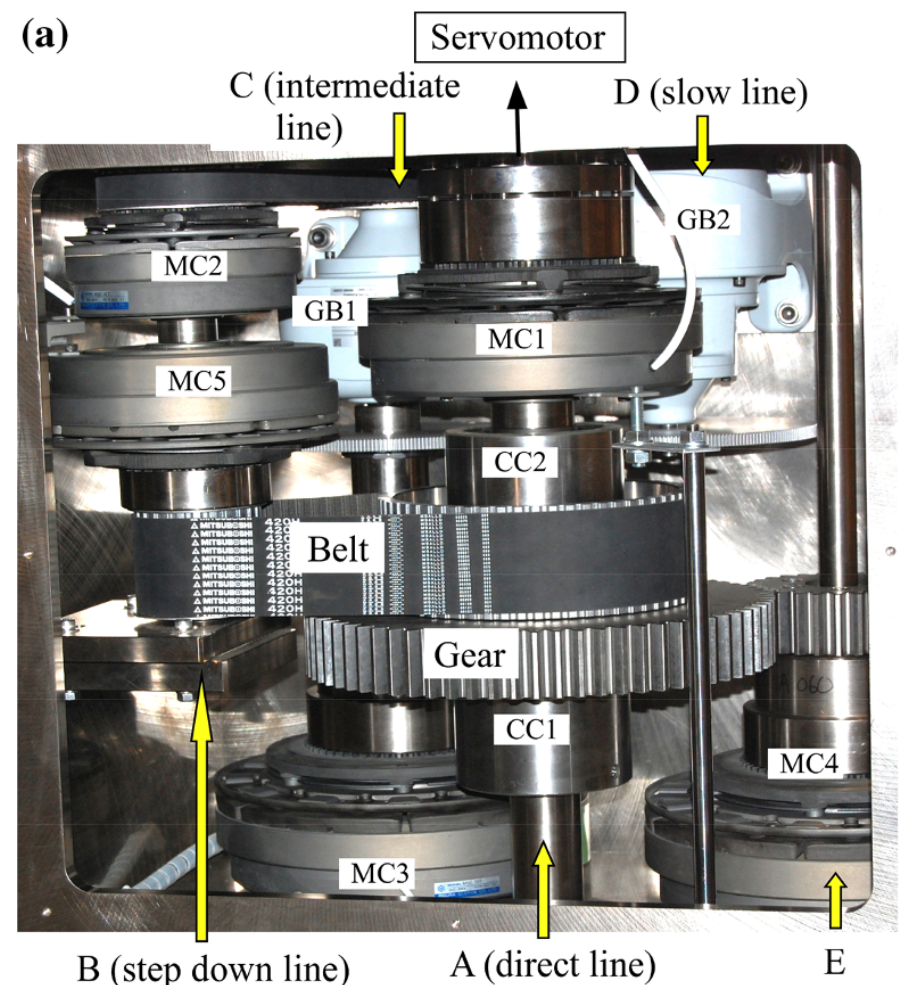

(b) Roles of a cam clutch

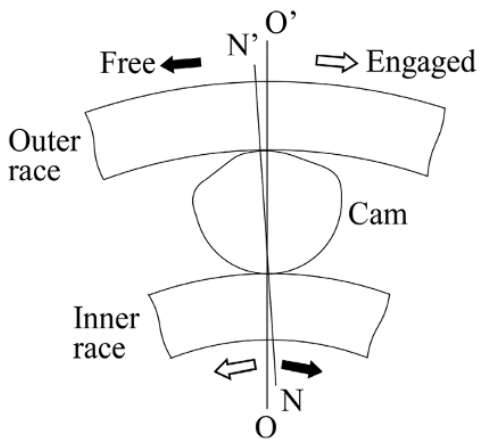

(c) Operations of a cam clutch

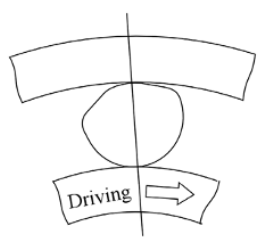

Direct line

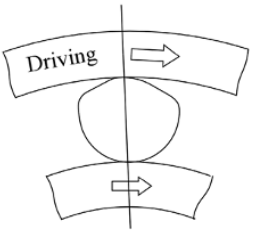

$1 / 5$ reduction line

Fig. 4 a A photograph of the gear/belt system, $\mathbf{b}$ a schematic figure showing roles of a cam clutch, and $\mathbf{c}$ figures showing operations of a cam clutch along a direct line (left) and 1/5 speed-reduction line (right). MC1-MC5 electromagnetic clutches with their numbers, GB1 and GB2 gear boxes with speed reductions of 1/200 and 1/300, respectively, CC1 and CC2: cam clutches, belt a belt in the 1/5 speed-reduction line, gear the final gear for speed reduction. Schematic figures were simplified from a product catalog of the cam clutches (Tsubaki, MZ-45)

$D$ and rotary shaft on line $E$ back to main line through the big gear. Drop from the fast line to the slow line can be done by disconnecting MC1, and turning on MC2 and MC4 simultaneously. Changing to faster lines can be done in similar manner.

A unique feature of our gear/belt system is the use of cam clutches, CC1 and CC2 (Tsubaki Cam Clutch, MZ-45 with a torque limit of 1,620 N m) in Fig. 4a, to mechanically reduce the velocity by five times and increase it back to the original velocity in the fast line. Velocity step tests are effective to separate instantaneous and transient responses of a fault that are described in rate-and-state friction law (Dieterich 1979; Ruina 1983). Our purpose was to achieve a five-time step change in velocity at high velocities (in the fast line). A cam clutch we used consists of inner and outer races separated by a series of cams with a geometry shown in Fig. 4b. The inner race is the rotary column in line $A$, and a belt and gear in the center are tied to the outer race of the $\mathrm{CC} 1$ and $\mathrm{CC} 2$, respectively (Fig. 4a). The line $\mathrm{OO}^{\prime}$ is drawn normal to the surfaces of the inner and outer races, whereas a cam is always in contact with the surfaces of the races at slightly inclined position by an action of a spring (not shown in the figure). $\mathrm{NN}^{\prime}$ is a line connecting the contacting point and deviates slightly leftward from the normal direction. Then clockwise motion of the inner race or anti-clockwise motion of the outer race, shown in filled arrows, rotates the cam anticlockwise and the cam does not get stuck to allow free movement of the races. Whereas anti-clockwise motion of the inner race or clockwise motion of the outer race, shown in open arrows, rotates the cam clockwise to get it stuck between the races. In such cases, the outer and inner races are engaged and a torque is transmitted between them.

When the direct line $A$ is active, the rotary column rotates clockwise as viewed from the top and can rotates freely even though a belt and a gear are connected to the outer races of $\mathrm{CC} 2$ and $\mathrm{CC} 1$, respectively (this is the case shown in the left diagram of Fig. 4c). A five-time reduction in velocity can be done by disconnecting $\mathrm{MC} 1$, and turning on MC2 and MC5 simultaneously. Then the rotary column (or the inner race) stops moving, and rotary motion is transmitted through MC2, MC5 and the big belt in the center to rotate the outer race of $\mathrm{CC} 2$ clockwise at the onefifth of the original speed. This is a rotation that engages $\mathrm{CC} 2$ and the rotary motion is transmitted to the central column. This is the case shown in the right diagram in Fig. $4 \mathrm{c}$ (the outer race is driving the motion of the inner race in this case). The velocity can be put back to its 
original value by connecting $\mathrm{MC} 1$, and disconnecting $\mathrm{MC} 2$ and MC5 simultaneously. Note that CC2 can allow fivetime velocity reduction and then five-times velocity increase in the fast line only. The role of CC1 is to connect the rotary motion of line $C$ (intermediate) or line $E$ (slow line) to the central column which can be done as follows. When MC1, MC3, and MC5 are off and MC2 and MC4 are on, rotary motion is transmitted from MC2, to GB1, to GB2 and line $E$, and to the final big gear which rotates the outer race of $\mathrm{CC} 1$ clockwise. This is the same case as in the right diagram of Fig. 4c, and the rotary motion is transmitted to the central column (i.e., the slow line is active). There is the same gear below GB1 connected to the central big gear, as that shown in the lower-right side of Fig. 4a, and this transmits the rotary motion to the central column when MC1 is off, and MC2 and MC3 are connected (the intermediate line is active).

Figure 5 exhibits an example of velocity-jump tests by changing gear/belt lines and a velocity step test with a cam clutch, conducted on the Punchbowl fault gouge (see Kitajima et al. (2010, 2011) for description of gouge) with specimens of Indian gabbro of $40 \mathrm{~mm}$ in diameter, at a normal stress of $1 \mathrm{MPa}$. Friction coefficient $\mu$ (or shear stress normalized by a normal stress) dropped abruptly from 0.48 to 0.02 upon a 1,000 -times reduction in velocity from $1 \mathrm{~mm} / \mathrm{s}$ to $1 \mu \mathrm{m} / \mathrm{s}$ (change from the intermediate line to the slow line), and then $\mu$ recovered gradually to 0.52 in about $170 \mathrm{~s}$ to show a velocity weakening behavior (Fig. 5a). On the other hand, a velocity jump from $1 \mu \mathrm{m} / \mathrm{s}$ to $1 \mathrm{~mm} / \mathrm{s}$ (from the slow to the intermediate line) leads to a typical step-change behavior described by a rate-andstate friction law (Fig. 5b); i.e., instantaneous increase in friction followed by a decay in friction to a nearly steadystate friction lower than $\mu$ before the step increase in velocity (velocity weakening). A similar behavior was recognized upon a step-increase in velocity from $1 \mathrm{~mm} / \mathrm{s}$ to $1 \mathrm{~m} / \mathrm{s}$ (from the intermediate to the fast line; left side of Fig. 5c). However, we will discuss if this instantaneous increase in friction reflects a rate-and-state frictional property or not later in this paper. No instantaneous change in friction was recognized when a velocity was reduced by five times using a cam clutch, but $\mu$ increased from 0.31 to about 0.48 in $0.65 \mathrm{~s}$, followed by gradual strengthening (middle part of Fig. 5c). A 200-time reduction in velocity from $0.2 \mathrm{~m} / \mathrm{s}$ to $1 \mathrm{~mm} / \mathrm{s}$ (from the cam clutch line to the intermediate line) caused another abrupt drop in $\mu$ (or shear stress) in $13 \mathrm{~ms}$ from 0.61 to 0.05 , followed by an increase to 0.65 in $38 \mathrm{~ms}$ (right side of Fig. $5 \mathrm{c}$, or an enlargement figure in Fig. 5d).

Five-times velocity reduction operated nicely without loss of torque although we have not used this capability fully in friction experiments. Velocity changes by 1,000 times with gear/belt lines worked fine when a velocity was increased, but the shear stress dropped to nearly zero when a velocity was decreased. We are not completely sure what caused the difference, but the following may be a possibility. For instance, all lines in Fig. 4a are under a torque when the low-velocity line is active, and an operation of velocity increase to the intermediate line is cutting the lines shorter by connecting MC3 and turning off MC4. The torque will not be lost as long as the turning on and off of the clutches occur nearly simultaneously, and this is probably the reason why a torque was not lost upon a velocity increase. We use electric switches for the clutches which act almost instantly. On the other hand, lines $D$ and $E$ in Fig. 4a are not under a torque when the intermediate velocity line is active because MC4 is disconnected, and the gear above MC4 keeps rotating without transmitting a torque to the column in line $E$. The gears in line $D$ and the column in line $E$ also keep rotating freely from a torque since they are connected to GB1 with the two thin gears near the center of Fig. 4a. A velocity reduction by connecting MC4 and turning off MC3 makes the loose lines $D$ and $E$ into the loading system, and clearances between gears and parts probably removed the torque in the loading system. Whatever the cause, the velocity reduction by changing gear/belt lines cannot be achieved without loss of torque at present. However, velocity increase or decrease by more than three orders of magnitude can be done by changing the speed of the servomotor. Our apparatus is equipped with an analog device to change the voltage controlling the motor speed in 9,999 steps which allows fine speed changes of the servomotor. We also use a function generator (NF Corporation, DF1906) for making arbitrary changes of voltage to control the slip history. We plan to install a servo-controlled system for the servomotor shortly.

\subsection{A pressure vessel for controlled pore-pressure experiments}

Figure $6 \mathrm{a}$ and $\mathrm{b}$ show a photograph of a pressure vessel for room temperature experiments and its schematic diagram, respectively (numbers denote parts in the explanation below). Pressure vessel consists of a vessel itself with inner and outer diameters of 65 and $96 \mathrm{~mm}$, respectively (1), upper and lower glands with two O-rings (2 and 3), and upper and lower nuts to hold the glands (4 and 5). A pair of specimens of $40 \mathrm{~mm}$ in diameter are put in the center (stippled) between the upper and lower pistons of $15 \mathrm{~mm}$ in diameter (6 and 7). There are specimen holders, shown on the right side of Fig. $6 \mathrm{c}$, between the specimens and the pistons, and the inner ends of the pistons act as holders of the two specimen holders. A key groove of $10 \mathrm{~mm}$ in width on a specimen (a photograph in the center of Fig. 6c) is put over a key of the specimen holder to prevent the rotation of 

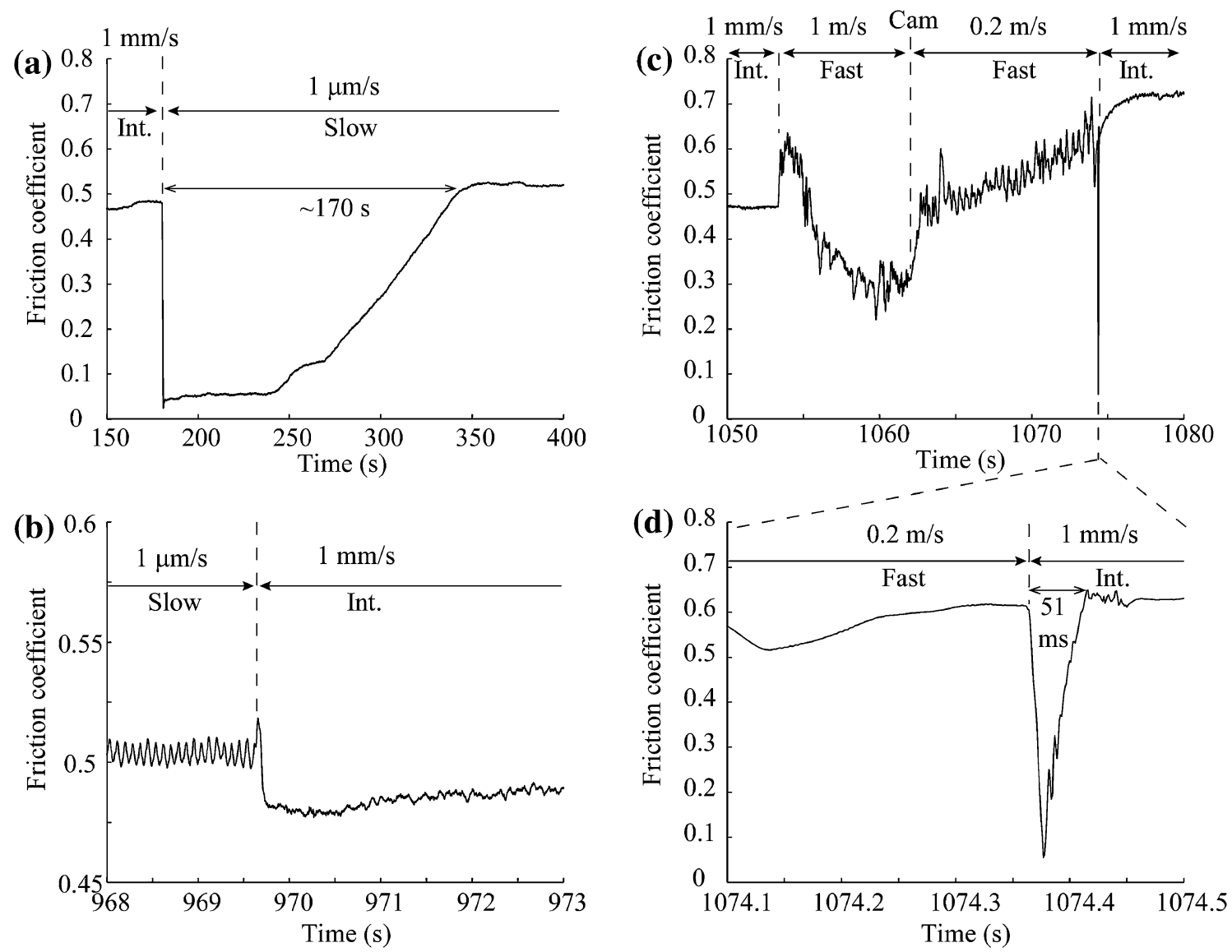

Fig. 5 Friction coefficient plotted against time during a velocity-jump test conducted on Punchbowl fault gouge with gabbro host-rock specimens under room humidity at a normal stress of $1 \mathrm{MPa}$ and at slip rates given on each curve. Only parts of the experiment are shown here using time from the onset of the test on the horizontal axes, to highlight the behaviors at step changes in slip rates, either by changing gear/belt line or by using a cam clutch. Gear/belt lines are specified by "Slow", "Int.", and "Fast" indicating slow, intermediate and fast gear/belt assembly, and "CAM" indicates a five-times velocity reduction using a cam clutch. $\mathbf{d}$ Close-up of the dashed-line portion in $\mathbf{c}$

the specimen in rotary-shear experiments. The upper and lower specimen holders are connected to the upper and lower pistons in similar manner with keys. A variety of specimen holders (e.g., metal specimen holders for gouge experiments) can be made as long as they can be set to the pistons with keys. We used six ball bearings in total around the upper/lower specimen holders and the pistons to allow easy rotary motion and to fix specimen holders within the inner wall of the pressure vessel; one of the ball bearings can be seen in a photograph on the right side of Fig. 6c. A small ball bearing is also set on top of the upper gland (2) to hold the rotating piston in place. The upper and lower pistons are set to rotary column and to a metal spacer (9), respectively, with ETB hub-shaft connections of Miki Pully (8). Metal spacer is tied to the axial loading column (8 in Fig. 2) with a larger ETB hub-shaft connection, and three thermocouples and a pore-pressure gauge are set to the spacer. The three thermocouples are inserted into a hole in the lower piston to measure temperature at the inside of the sliding surface and inside of the stationary specimen.
In rotary shear experiments, it is important to have a good linear alignment of the loading column and to hold specimens to prevent its lateral vibration caused by misalignment of the loading column. A metal ring (10) is screwed into the thread on the outside of the pressure vessel which can be seen in the center of Fig. 6a. After the position of the ring or the position of the pressure vessel is adjusted, the ring is fixed by tightening a nut against the ring using the same screw. The thread on the outside of the vessel is used for the upper and lower nuts (4 and 5) too. Then the metal ring (10) with the pressure vessel is bolted to a circular plate (11) which is fixed to the aluminum frame (12) with bolts. The aluminum frame is bolted to a horizontal plate of the apparatus (see bottom of Fig. 6a). The ring (10) and the plate (11) are in spherical contact which allows adjustment of the axial inclination of the pressure vessel, and holes for bolts in the plate (11) and the frame (12) are made bigger than the diameters of bolts for fine adjustment of the horizontal position of the assembly. The bottom end of the rotary column and upper end of the 

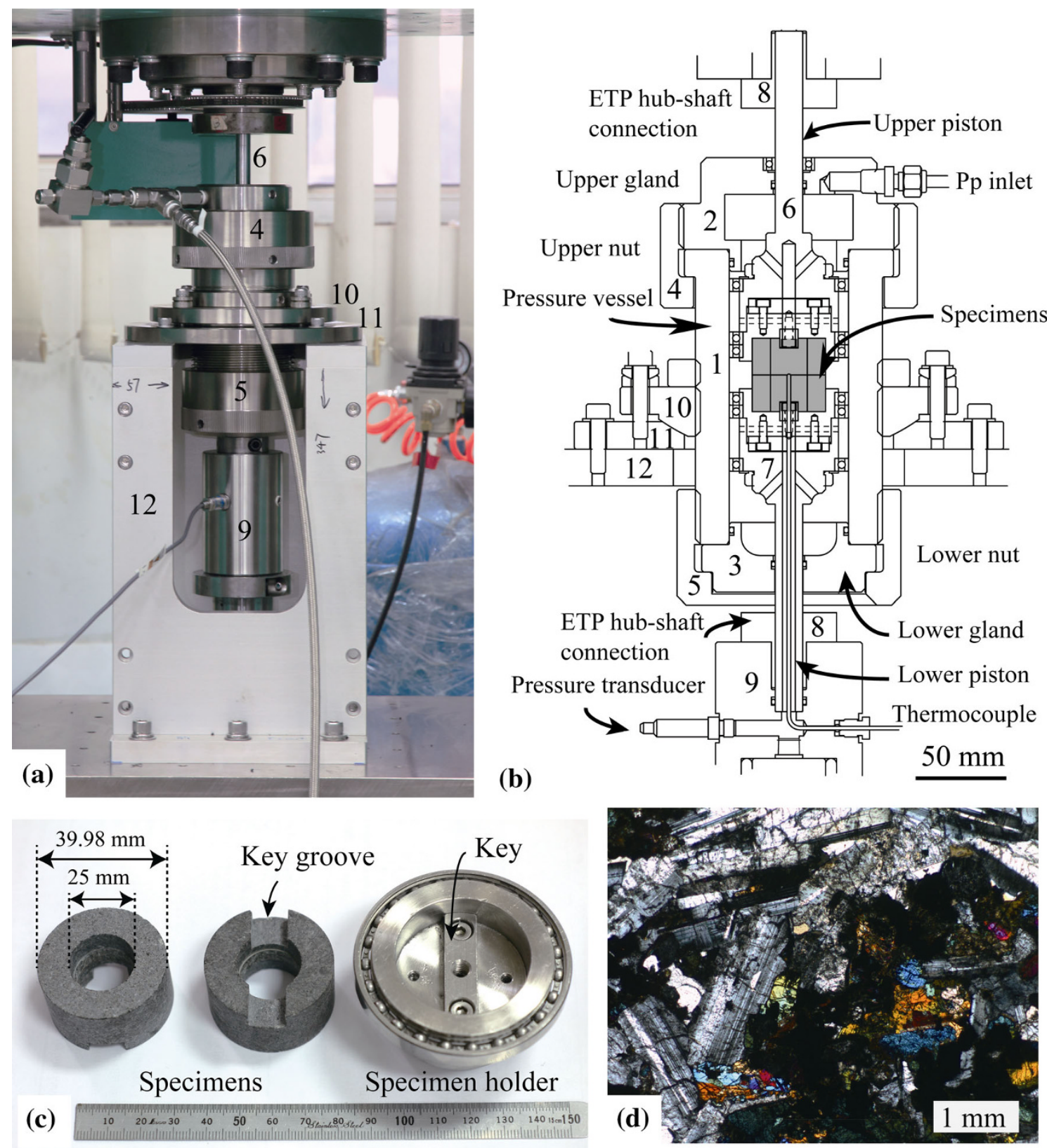

Fig. 6 a A photograph of a pressure vessel for controlled pore-pressure experiments, $\mathbf{b}$ a schematic diagram of the pressure vessel, $\mathbf{c}$ a photograph of a hollow-cylindrical specimen of Shanxi dolerite with sliding surface on top (left), a specimen with a key groove on the opposite side of the sliding surface (middle), and a specimen holder with a ball bearing outside (right), and $\mathbf{d}$ a photomicrograph of Shanxi dolerite with an ophitic texture under crossed-polarized light. Numbers in $\mathbf{a}$ and $\mathbf{b}$ are reference numbers for parts used in the explanations in the text

axial loading pistons are the two reference points to which the upper piston (6) and the metal spacer (9) have to be adjusted within several microns. The pressure vessel is fixed to the aluminum frame just outside of the specimen assembly, almost eliminating the vibration of pressure vessel.

The pressure vessel is connected to a water reservoir and bottles of gases such as $\mathrm{N}_{2}, \mathrm{Ar}$ and $\mathrm{H}_{2}$. A gas booster is used to pressurize confining medium to around $100 \mathrm{MPa}$, but pressure-release valves at $35 \mathrm{MPa}$ are set in the pressurization system for safety at present. No jackets are used in most rotary-shear experiments, so that a confining pressure acts as pore pressure (called simply "pressure" $P$ hereafter) and a normal stress $\sigma_{\mathrm{n}}$ is applied by an axial load (effective normal stress $\sigma_{\mathrm{n}}^{\mathrm{e}}=\sigma_{\mathrm{n}}-P$ ). Thus, an interaction between $P$ and an axial force $F$ is inevitable because $P$ imposes an axial load to the upper and lower pistons. To calibrate the axial force due to the pressure, 

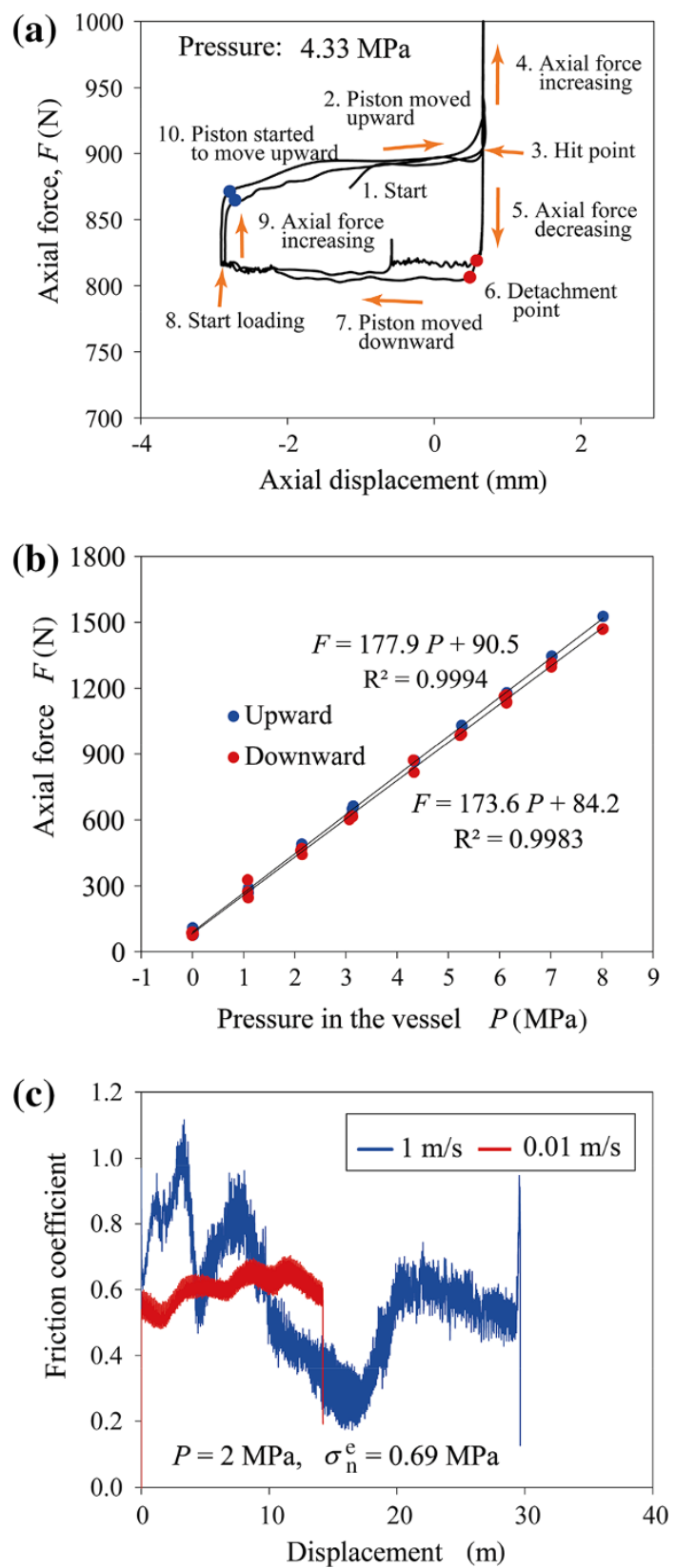

Fig. 7 a A calibration record for the axial force and displacement at a water pressure of $4.33 \mathrm{MPa}$, during axial-load cycling to determine the hit point of the piston to the specimen, $\mathbf{b}$ axial forces $F$ at a detachment of the two specimens during unloading (red circles) and at the initiation point of the axial shortening of the piston (blue circles) plotted against the pressure $P$ in the vessel, and c friction coefficients versus displacement curves for two runs at slip rates as shown in the diagram and at a water pressures $P=2 \mathrm{MPa}$, a normal stress $\sigma_{\mathrm{n}}=2.69 \mathrm{MPa}$, and an effective normal stress $\sigma_{\mathrm{n}}^{\mathrm{e}}=0.69 \mathrm{MPa}$. The solid lines and equations in $\mathbf{b}$ are the least-squares fit to the data with correlation coefficients $R$

$P$ of $4.33 \mathrm{MPa}$ was applied first, an axial column was loaded at point 1 in Fig. 7a and the column started to move upward along 2 (i.e., an axial force $F$ increased slightly with an increase in the displacement), and at point 3 the axial shortening nearly stopped and $F$ began to increase sharply. The point 3 is the hit point where the lower specimen hits the upper specimen to increase the axial load in the loading column. Then $F$ was decreased along 5 with almost no change in the displacement to point 6 where $F$ stopped decreasing and the axial displacement began to decrease along 7 . We started loading at point 8 to increase $F$ to point 9 where $F$ stopped increasing rapidly and the displacement began to increase to another hit point. The same cycling was repeated twice. The two specimens detached at point 6 , and the loading column began to move upward at point 9. The difference between red and blue circles in Fig. 7a must be due to the O-ring friction to the lower piston, and if that is the case the axial force $F$ due to $P$ must be a force between those points. Figure $7 \mathrm{~b}$ exhibits $F$ plotted against $P$ which gives $F=177.9 \quad[\mathrm{~N} /$ $\mathrm{MPa}] \times P[\mathrm{MPa}]+90.5[\mathrm{~N}]$ for loading and $F=173.6$ $[\mathrm{N} / \mathrm{MPa}] \times P[\mathrm{MPa}]+84.2[\mathrm{~N}]$ for unloading (solid lines) with very high correlation coefficient $R$. The diameter of lower piston $(15 \mathrm{~mm})$ yields $F=176.7 P$ which is very close to an average of the slope of the fitted lines (175.6). We do not know exactly what causes a slight increase in $F$ from point 9 to 3 in Fig. 7a, but we determined an effective normal stress $\sigma_{\mathrm{n}}^{\mathrm{e}}$ by subtracting from the measured axial force by the force at the hit point. The hit point should be determined for each run for accurate estimate of $\sigma_{\mathrm{n}}^{\mathrm{e}}$. The intercepts of the fit lines in Fig. $7 \mathrm{~b}$ are due to the weight of the axial loading columns because we did not reset the output from the axial force gauge (12 in Fig. 2) during the calibration. The force gauge output is reset to zero before applying the normal stress in friction experiments.

Figure 7c shows two examples of experiments on Shanxi dolerite with ophitic textures of plagioclase (Fig. 6d), conducted at a pore water pressure $P$ of $2 \mathrm{MPa}$ and an effective normal stress $\sigma_{\mathrm{n}}^{\mathrm{e}}$ of $0.69 \mathrm{MPa}$. A run at a seismic slip rate of $1.0 \mathrm{~m} / \mathrm{s}$ exhibits a gradual increase in friction coefficient $\mu$ to about 1.1 , followed by two weakening-strengthening behaviors with the minimum $\mu$ of around 0.25 (width of the curve reflects the fluctuation of $\mu$ with revolution of the specimen). Similar weakeningstrengthening behaviors of dry gabbro are reported by Hirose and Shimamoto (2005) and Brown and Fialko (2012). At a subseismic slip rate of $0.01 \mathrm{~m} / \mathrm{s}, \mu$ increases from 0.54 to 0.65 with fluctuations and no marked weakening occurred at this rate. Frictional behaviors with pore water pressure will be reported elsewhere.

\section{Velocity-jump tests on Pingxi fault gouge}

Most IHV friction experiments have been conducted at constant slip rates (e.g., Di Toro et al. 2011). However, slip history does affect frictional behavior as demonstrated by 
Sone and Shimamoto (2009), and Fukuyama and Mizoguchi (2010). We explore here a slip history starting from slow initial slip at a slip rate of $1.4 \mathrm{~mm} / \mathrm{s}$ and then abruptly increasing to $1.4 \mathrm{~m} / \mathrm{s}$. The velocity step is by three orders of magnitude and we call our experiments "velocity jump tests." Such jumps may be expected when a fault undergoing slow slip becomes unstable or when an earthquake rupture front comes from elsewhere. The velocity jump was attained by changing the belt/gear assembly from the middle-speed mode to fast-speed mode without loss of torque in the loading column within a fairly short period of time $(\sim 0.15 \mathrm{~s})$.

We used yellowish in color gouge (YG) from a Pingxi fault zone at the Kuangpingzi outcrop, located near northeastern end of the surface ruptures activated during the 2008 Wenchuan earthquake. YG is one of the beststudied gouges from the Longmenshan fault system, Sichuan province, China, after the earthquake (see Yao et al. 2013a; Chen et al. 2013a, c) for the description of the fault-zone structures at this outcrop and the gouge used in experiments). YG is composed of calcite (59\%), quartz $(21 \%)$, dolomite $(11 \%)$, illite $(5 \%)$, barite $(3 \%)$, and other subsidiary minerals, with a grain size of $8.0 \mu \mathrm{m}$ at a frequency of $50 \mathrm{vol} \%$ (Yao et al. 2013a; Fig. 5). Gouge powders for tests were prepared by crushing and sieving (100\# sieve, $150 \mu \mathrm{m})$ the air-dry gouge pieces without grinding them severely. The Indian gabbro (see Hirose and Shimamoto 2005 for its mineralogy) was cored and ground with a cylindrical grinder to make solid cylindrical specimens of $40 \mathrm{~mm}$ in diameter. The sliding surfaces of gabbro cylinders were ground on a surface grinder with a diamond wheel of $150 \#(100 \mu \mathrm{m})$. We roughened the sliding surface of only a few sets of specimens by grinding with $80 \# \mathrm{SiC}$ $(180 \mu \mathrm{m})$ on a glass plate by hand, because we worried that the specimen ends might not become normal to the cylinder axis by manual roughening, causing misalignment of the specimens. We refer the former as "smooth" sliding surfaces (or "smooth" gabbro cylinders) and the latter as "rough" sliding surfaces below. Experiments were done using a Teflon sleeve to confine $2.5 \mathrm{~g}$ of the air-dried gouge (1.0-1.3 $\mathrm{mm}$ in thickness), using procedures described in Yao et al. (2013a, b). Appendix explains our procedures for correcting the measured shear stress for the Teflon-specimen friction (called Teflon friction hereafter). This paper is focused on our LHV apparatus, and some experimental results are interpreted and discussed in this section to avoid mixing discussions on the apparatus and friction experiments.

\subsection{Velocity-jump tests on the yellowish gouge (YG)}

Evolution of friction coefficient $\mu$ in four representative tests with smooth sliding surfaces of gabbro, conducted at normal stresses of $0.45,0.8,1.0$, and $1.7 \mathrm{MPa}$, is shown against time in Fig. 8a and against displacement in Fig. 8b. For comparison, three tests were conducted on YG with roughened surfaces of gabbro cylinders at the same normal stresses, and Fig. 8c and d exhibits the results in the same manner as those in Fig. 8a and b. Duration of the sliding at the low slip rate of $1.4 \mathrm{~mm} / \mathrm{s}$ was about $30 \mathrm{~s}$ and hence the displacement was only about $42 \mathrm{~mm}$, so that the initial slow slip portions cannot be seen clearly in Fig. $8 \mathrm{~b}$ and $\mathrm{d}$. Teflon friction during the velocity jump tests was corrected based on a similar test on Teflon sleeve shown in Fig. 12 (see Appendix).

In the first several seconds after the onset of the tests, YG exhibits initial peak friction coefficients of $0.12-0.28$ with smooth sliding surface (Fig. 8a) and of $0.15-0.23$ with rough sliding surface (Fig. 8c), followed by slight reduction in friction for about $5 \mathrm{~s}$. These strange initial evolutions of friction are probably related to the initial compaction of gouge because we did not pre-compacted gouge before a run (see the axial shortening data at the bottom). Then the friction coefficient $\mu$ begins to increases to $0.39-0.47$ for smooth surface and to $0.59-0.63$ for rough surface after which $\mu$ stays at about the same level although slight weakening occurred in some runs (Fig. 8a, c). The axial shortening data indicate that the gouge compaction (or axial shortening) continues for 10-15 s and nearly diminishes, and the onset of nearly steady-state friction corresponds to the diminishing compaction of gouge. We interpret that the initial small peak friction is related to the yielding of gouge to allow the onset of slip and subsequent gradual increase in friction due to compaction-induced strengthening of gouge. Such behaviors are not recognized very often in tests with pre-compacted gouge. We thought initially that the slight weakening after the first small peak friction might be an apparent phenomenon arising from the initial peak friction of Teflon sleeve which decays rapidly in several seconds (Fig. 12a, see Appendix), about the same time interval for the initial gouge weakening. But the friction curves in Fig. 8a and c were corrected for the Teflon friction (see Appendix) and the behaviors reflect a gouge property. YG with rough surface exhibits higher friction coefficients at the first and second levels of friction than YG with smooth surface (cf. Fig 8a, c). The nearly steady-state friction coefficient $\mu_{\mathrm{ss}}$ at the end of the sliding at $1.4 \mathrm{~mm} / \mathrm{s}$ is given on the fifth column of Table 2 which yields an average $\mu_{\text {ss }}$ of $0.43 \pm 0.034$ and $0.62 \pm 0.02$ for smooth and rough sliding surfaces, respectively (the error is one standard deviation). Thus, $\mu_{\mathrm{ss}}$ for the rough surfaces is greater than that for the smooth surfaces by 0.19 on the average.

Friction increases rapidly for YG with smooth surface upon a velocity jump from $1.4 \mathrm{~mm} / \mathrm{s}$ to $1.4 \mathrm{~m} / \mathrm{s}$ (Fig. $8 \mathrm{a}$ ). This change in friction for the test LHV076 is shown in an enlarged diagram where friction coefficient increased from 
0.45 to 0.57 in $0.15 \mathrm{~s}$, about the same time interval for the velocity increase (inset diagram of Fig. 8a). This is similar to an instantaneous response described in the rate-and-state friction law (e.g., Dieterich 1979, 1981; Marone 1998; Nakatani 2001). The constitutive parameter $a$ describing the instantaneous response is defined by $a=\Delta \mu / \ln \left(v / v_{0}\right)$, where $\Delta \mu$ is an instantaneous change in friction coefficient when slip rate increases instantly from $v_{0}$ to $v$. Specimentesting machine interaction has to be solved to determine $a$ precisely because the velocity jump is not an ideal step increase and elastic deformation of testing machine affects the behavior (see Noda and Shimamoto 2009; references therein). This is not easy at present because the constitutive equation is not established fully in high-velocity regime and the stiffness of our machine, including the effect of servo-motor, is not determined yet. However, the result in Fig. 8a gives $a$ of about $0.017 \quad[a=(0.569-0.452) /$ $\ln (1,000)=0.017]$ for the test LHV076 assuming that our velocity jump by three orders of magnitude was an ideal step and that the rapid increase in friction gives the instantaneous response. Typical values for $a$ from slow slip-rate experiments are 0.005-0.03 (Nakatani 2001, p. 13349), so that the above $a$ value from a velocity jump test is within this range.

The amount of abrupt increase in friction coefficient upon the velocity jump is summarized in Fig. 8e and its vertical axis on the right side gives $a$ values as determined above. Results from 10 experiments on YG with smooth sliding surface yield $a$ in the range of 0.0043-0.026 with an average of $0.017 \pm 0.0056$, the error being one standard deviation. Only selected friction coefficient versus time or displacement curves are shown in Fig. 8a and b, but slip weakening parameters and $a$ values are summarized in Table 2. A very interesting unexpected result was that the rapid increase in friction upon the velocity jump was not recognized for the same YG with rough host-rock sliding surfaces (Fig. 8c, d). A run LHV209* conducted at a normal stress of $0.45 \mathrm{MPa}$ exhibits an increase in friction coefficient of 0.02 (Fig. 8e; runs with rough surfaces are shown with asterisks in Table 2). But this change is of the same order as the instantaneous change in Teflon friction (Fig. 12a, see Appendix), so that the accuracy of our experiments is not enough to resolve this because of possible variation of the Teflon friction from run to run (see Appendix). However, the marked contrast in the response to velocity jump between smooth and rough host-rock surfaces is much larger than the Teflon friction and we consider it real.

The subsequent evolutions of frictional behavior at slip rates of $1.4 \mathrm{~m} / \mathrm{s}$ are similar to those from regular highvelocity experiments at constant slip rates for the same gouge materials (Yao et al. 2013a). In particular, the slip weakening parameters (peak and steady-state friction coefficients, $\mu_{\mathrm{p}}$ and $\mu_{\mathrm{ss}}$, and slip-weakening distance $D_{\mathrm{c}}$ ) and the specific fracture energy $E_{\mathrm{G}}$ for the rough sliding surfaces in Table 2 are about the same as those of YG for the rough surfaces, reported in Yao et al. (2013a, Figs. 7, 8). However, $\mu_{\mathrm{p}}$ for the smooth surfaces at $1.4 \mathrm{~m} / \mathrm{s}$ is $0.55 \pm 0.025$, as compared with $0.63 \pm 0.015$ for the rough surfaces. Thus, $\mu_{\mathrm{p}}$ of YG with the smooth surfaces is still smaller than that for the rough surfaces, but the difference (0.08) is distinctly smaller than the difference in $\mu_{\mathrm{ss}}$ at end of the sliding at $1.4 \mathrm{~mm} / \mathrm{s}$ (0.19). Moreover, YG with smooth and rough surfaces exhibits similar slipweakening behaviors characterized by $D_{\mathrm{c}}$ and $\mu_{\mathrm{ss}}$ (cf. Fig 8b, d), so that high-velocity friction of YG seems to become rather insensitive to the surface roughness.

On the other hand, nearly steady-state friction coefficient just before the velocity jump is lower for YG with smooth surface than that with rough surface by 0.19 . This raises another possibility for interpreting the rapid increase in friction with velocity jump for the YG with smooth surface; that is, an abrupt increase in friction could be an increase from somewhat lower friction of YG at a slip rate of $1.4 \mathrm{~mm} / \mathrm{s}$ to a higher level friction at $1.4 \mathrm{~m} / \mathrm{s}$. Friction coefficient of YG with rough surface at $1.4 \mathrm{~mm} / \mathrm{s}$ $(0.62 \pm 0.02)$ is nearly the same as the peak friction coefficient at $1.4 \mathrm{~m} / \mathrm{s}(0.63 \pm 0.015$; see Table 2$)$, and the notable increase in friction upon the velocity jump might not have occurred in this case. Whereas for $\mu_{\mathrm{ss}}$ at $1.4 \mathrm{~mm} / \mathrm{s}$ and $\mu_{\mathrm{p}}$ at $1.4 \mathrm{~m} / \mathrm{s}$ are $0.43 \pm 0.034$ and $0.55 \pm 0.025$, respectively, with a difference of 0.12 which gave the above estimate of $a$. Thus, the abrupt increase in $\mu$ at the velocity jump can be interpreted as the change in friction at $1.4 \mathrm{~mm} / \mathrm{s}$ to that at $1.4 \mathrm{~m} / \mathrm{s}$.

We conducted two friction experiments at $1.4 \mathrm{~mm} / \mathrm{s}$ with displacements up to $300 \mathrm{~mm}$ to clarify the problem. The results in Fig. 8f indicate that YG with smooth surface has the initial friction coefficient smaller by about $0.10 \sim 0.15$ than that for YG with rough surface, but the friction coefficient becomes about the same at a displacement of about $160 \mathrm{~mm}$. The rapid increase in friction of YG with smooth surface occurred in about $0.15 \mathrm{~s}$ (e.g., inset diagram in Fig. 8a), during which displacement could exceed $100 \mathrm{~mm}$. This displacement plus the displacement at the time of velocity jump (42 $\mathrm{mm})$ are almost enough for making the friction coefficients of YG with smooth and rough surfaces to be about the same (Fig. 8f), although the effect of velocity acceleration in $0.15 \mathrm{~s}$ cannot be evaluated at this point. Thus, YG with smooth sliding surface could have increased simply from a low friction coefficient at a slow slip rate to a high-friction coefficient at a high slip rate upon the velocity jump. This scenario could be an alternative explanation for the rapid increase in friction with velocity jump to the interpretation using constitutive parameter $a$ in the above. The problem will be discussed further in Sect. 5 . 

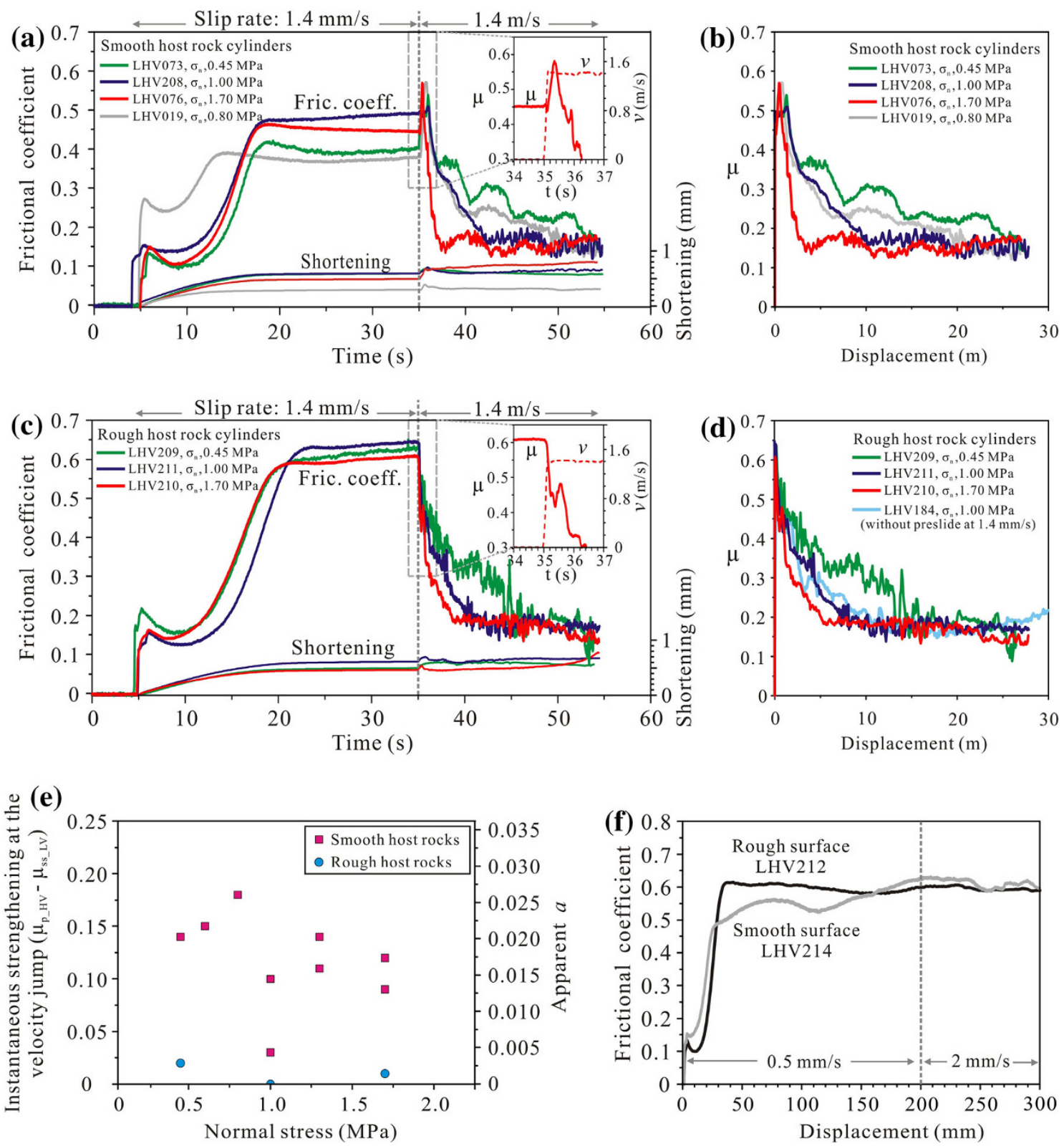

Fig. 8 Friction coefficient plotted $\mathbf{a}, \mathbf{c}$ against time, and $\mathbf{b}, \mathbf{d}$ against displacement for the yellowish gouge (YG) deformed at four normal stresses as shown in the figures and with a velocity jump from $1.4 \mathrm{~mm} / \mathrm{s}$ to $1.4 \mathrm{~m} / \mathrm{s}$ after $30 \mathrm{~s}$ from the onset of tests. Sliding surfaces of host rocks were ground smooth with diamond grinding wheel of 150\# (about $100 \mu \mathrm{m})$ for $\mathbf{a}$ and $\mathbf{b}$, and roughened with carborundum powder of 80\# (about $180 \mu \mathrm{m}$ ) for $\mathbf{c}$ and $\mathbf{d}$. The inset diagrams in a and $\mathbf{c}$ show enlargements of friction coefficient evolution (solid curves) and slip rate (dashed curves) upon the velocity jumps. A test conducted at a constant slip rate of $1.4 \mathrm{~m} / \mathrm{s}$ without preslide (Yao et al. 2013a, b; light blue curve) was plotted in $\mathbf{d}$ for comparison. e Nearly instantaneous increase in friction coefficient at the velocity jump plotted against the normal stress in squares for tests in $\mathbf{a}$ and $\mathbf{b}$, and in circles for those in $\mathbf{c}$ and $\mathbf{d}$. f Comparison of friction evolution of YG at low slip rates of $0.5-2 \mathrm{~mm} / \mathrm{s}$ using rough (black curve) and smooth (gray curve) sliding surfaces of host rocks. The data $\mathbf{f}$ were corrected for the Teflon friction by using the same procedures for the slow slip rate sliding (the initial presliding portion in Fig. 12)

\subsection{Mineralogical changes and deformation textures}

The YG deformed at high slip rates undergoes change in color from light yellow to grayish black on the outer part of the gouge layer, a typical appearance of Teflon decomposition (Fig. 9a; gouge deformed at $\sigma_{\mathrm{n}}=1.7 \mathrm{MPa}$, $v=1.4 \mathrm{~m} / \mathrm{s}$ with pre-sliding at $1.4 \mathrm{~mm} / \mathrm{s}$, run LHV076). XRD profiles of the undeformed gouges reveal the presence of calcite, dolomite, quartz, and illite for YG (Fig. 9b, bottom diagrams), whereas the deformed YG from the external 
Table 2 A summary of velocity-jump tests conducted on the yellowish gouge (YG) from a Pingxi fault zone with solid-cylindrical specimens of Indian gabbro

\begin{tabular}{|c|c|c|c|c|c|c|c|c|c|c|}
\hline \multirow[t]{2}{*}{ Run no. } & \multirow[t]{2}{*}{ Material } & \multirow[t]{2}{*}{$\sigma_{\mathrm{n}}(\mathrm{MPa})$} & \multicolumn{2}{|c|}{ Low slip rate } & \multicolumn{5}{|c|}{ High slip rate } & \multirow{2}{*}{$\begin{array}{l}\text { Apparent } a \\
\text { value }\end{array}$} \\
\hline & & & $v(\mathrm{~mm} / \mathrm{s})$ & $\mu_{\mathrm{ss}}$ & $v(\mathrm{~m} / \mathrm{s})$ & $\mu_{\mathrm{p}}$ & $\mu_{\mathrm{ss}}$ & $D_{\mathrm{c}}(\mathrm{m})$ & $E_{\mathrm{G}}\left(\mathrm{MJ} / \mathrm{m}^{2}\right)$ & \\
\hline LHV073 & YG & 0.45 & 1.40 & 0.398 & 1.40 & 0.538 & N/A & N/A & N/A & 0.020 \\
\hline LHV209* & YG & 0.45 & 1.40 & 0.622 & 1.40 & 0.637 & $0.125 \pm 0.001$ & $23.13 \pm 0.11$ & 1.76 & 0.002 \\
\hline LHV068 & YG & 0.60 & 1.40 & 0.359 & 1.40 & 0.510 & $0.110 \pm 0.002$ & $14.42 \pm 0.38$ & 1.15 & 0.022 \\
\hline LHV019 & YG & 0.80 & 1.40 & 0.414 & 1.40 & 0.592 & $0.187 \pm 0.002$ & $8.55 \pm 0.27$ & 0.92 & 0.026 \\
\hline LHV208 & YG & 1.00 & 1.40 & 0.482 & 1.40 & 0.509 & $0.155 \pm 0.001$ & $10.61 \pm 0.20$ & 1.25 & 0.004 \\
\hline LHV211* & YG & 1.00 & 1.40 & 0.639 & 1.40 & 0.641 & $0.176 \pm 3 e-4$ & $7.90 \pm 0.03$ & 1.22 & $3 e-4$ \\
\hline LHV066 & YG & 1.30 & 1.40 & 0.442 & 1.40 & 0.552 & $0.125 \pm 0.002$ & $4.04 \pm 0.13$ & 0.75 & 0.016 \\
\hline LHV067 & YG & 1.30 & 1.40 & 0.425 & 1.40 & 0.556 & $0.141 \pm 0.002$ & $4.02 \pm 0.20$ & 0.72 & 0.019 \\
\hline LHV076 & YG & 1.70 & 1.40 & 0.452 & 1.40 & 0.569 & $0.155 \pm 0.001$ & $3.17 \pm 0.08$ & 0.74 & 0.017 \\
\hline LHV086 & YG & 1.70 & 1.40 & 0.458 & 1.40 & 0.548 & $0.162 \pm 0.002$ & $2.47 \pm 0.14$ & 0.54 & 0.013 \\
\hline LHV210* & YG & 1.70 & 1.40 & 0.600 & 1.40 & 0.607 & $0.172 \pm 2 \mathrm{e}-4$ & $5.05 \pm 0.02$ & 1.24 & 0.001 \\
\hline LHV072 & YG & 1.00 & 2.09 & 0.436 & 2.09 & 0.536 & $0.091 \pm 0.001$ & $4.34 \pm 0.08$ & 0.64 & 0.015 \\
\hline
\end{tabular}

Symbols are $\sigma_{\mathrm{n}}$ normal stress, $v$ slip rate, $\mu_{\mathrm{p}}$ peak friction coefficient, $\mu_{\mathrm{ss}}$ steady-state friction coefficient, $D_{\mathrm{c}}$ slip-weakening distance, $E_{\mathrm{G}}$ specific fracture energy, and $a$ constitutive parameter in rate-and-state-dependent friction law describing an instantaneous response in friction upon a step change in slip rate. $\mu_{\mathrm{ss}}$ for the low slip rate is the mean value of friction coefficient during nearly steady-state frictional sliding prior to the velocity jump. See Mizoguchi et al. (2007) for the definitions of the slip weakening parameters $\mu_{\mathrm{p}}, \mu_{\mathrm{p}}$ and $D_{\mathrm{c}}$, and for the specific fracture energy $E_{\mathrm{G}}$

A slip rate was abruptly changed from $1.4 \mathrm{~mm} / \mathrm{s}$ to $1.4 \mathrm{~m} / \mathrm{s}$ (1,000-times) after sliding for $30 \mathrm{~s}$ at the slow rate. An asterisk on run number indicates a test using rough sliding surfaces, roughened with carborundum powders of 80\# $(180 \mu \mathrm{m})$, whereas other tests were conducted using smooth sliding surface ground with a diamond grinding wheel of $150 \#(100 \mu \mathrm{m})$ on a surface grinder

portion of the gouge layer exhibits almost no peaks of illite, reduced peaks of calcite and dolomite, and fluorite peaks (top diagrams). The results suggest that dehydration of illite occurred due to frictional heating, that part of calcite and possibly dolomite decomposed as reported by Han et al. (2007a), and that a small amount of fluorite formed through a reaction of decomposition products of calcite and Teflon. We also measured carbon content in the marginal portion of the deformed YG using a total organic carbon analyzer (Shimadzu, TOC-VCPH) at Institute of Tibetan Plateau Research, Chinese Academy of Science. We detected a reduction in inorganic carbon content from $7.42 \%$ to $3.36 \%$ for the YG, whereas the total carbon content increased slightly from $7.62 \%$ to $7.70 \%$ for YG, despite that the carbon contents are expected to decrease during highvelocity tests by decomposition of carbonate minerals (Han et al. 2007a) or oxidation reaction (Oohashi et al. 2011). Hence carbon supply by up to a few to several percent is needed to maintain or slightly increase the total carbon, and the decomposed Teflon is a possible source of carbon. Thus, the Teflon decomposition definitely occurred in our high normal-stress runs, but the decomposition is unlikely to have changed the gouge behaviors significantly as demonstrated by Kitajima et al. (2010).

We report deformation textures of YG with smooth sliding surfaces deformed at a normal stress of $0.8 \mathrm{MPa}$ and a slip rate of $1.4 \mathrm{~m} / \mathrm{s}$ (LHV019; Fig. 10) as a representative example and compare the textures with those of YG with rough surfaces reported by Yao et al. (2013a, b). Observations were made on a thin section going through the center of the specimen and parallel to the cylinder axis, under a field-emission environmental SEM (Quanta200F). This orientation of thin section is useful for observation of spatial variations of deformation textures from the center to the margin, as demonstrated by Kitajima et al. (2010) on experimentally deformed Punchbowl fault gouge, but shear textures cannot be observed because we are looking at a section normal to the movement direction. The gouge zone consists of (1) highly deformed zone with variable widths and the maximum width of $310 \mu \mathrm{m}$ adjacent to the rotary side of the specimen and (2) weakly deformed gouge with scattered clasts (Fig. 10a; gouge zone is $1.07 \mathrm{~mm}$ thick, the photograph covers the distances of $15 \mathrm{~mm}$ (left) to $20 \mathrm{~mm}$ (right) from the specimen center). Clasts of various sizes are scattered in the weakly deformed gouge and some of them are larger than $100 \mu \mathrm{m}$, close to the maximum particle size in the deformed YG gouge $(150 \mu \mathrm{m})$. The lower part of gouge adjacent to the stationary specimen appears to be slightly less deformed than the upper part of gouge in view of the sizes of scattered clasts. Another notable texture is a clay-clast aggregate (CCAs) characterized by a clast surrounded by cortex consisting of phyllosilicates-rich gouge aligned nearly parallel to the margin of clasts (Fig. 10d), a characteristic 
texture reported since Boutareaud et al. (2010) (see Han and Hirose 2012; references therein). CCAs are scattered in weakly deformed gouge. Energy-dispersive X-ray analysis indicates that the central clast is quartz and the cortex consists of ultra-fine calcite and clay minerals in Fig. 10d.

Highly deformed zone consists of ultrafine-grained zones that appear white on the photomicrograph, alternated with slightly coarser-grained zones consisting of grains mostly of several microns in size (Fig. 10b, c). The ultrafine-grained zones are composed of ultrafine particles mostly less than $1 \mu \mathrm{m}$ in size similar to those reported in Fig. 5d and $\mathrm{j}$ in Yao et al. (2013b), and we interpret them as slip zones accommodating fault slip. The particles gradually coarsen from an ultrafine-grained layer to the coarser-grained layer forming a slip-zone unit. Highly deformed zone consists of complex network of slip zones, often called "overlapped slip zones" (Togo et al. 2011; Togo and Shimamoto 2012; Sawai et al. 2012; Yao et al. 2013a, b); at least seven slip-zone units are recognized Fig. 10b. Shimamoto and Togo (2012) proposed that the strengthening of a slip zone due to shear-induced compaction and/or sintering of gouge particles due to frictional heating make the shearing of the thin slip zone difficult, resulting in the shift of slip zone to weaker and less deformed gouge and complex deformation of existing slip zones. Togo and Shimamoto (2012, Fig. 9) demonstrated that grains in the coarser-grained zones are welded or sintered, and this is probably the reason for the coarsergrained zone to have behaved as a unit with the ultrafinegrained slip zone. The slip-zone structures are quite heterogeneous even within Fig. 10a, and are completely different on the other side of the thin section from the specimen center. The overall textures of YG with smooth sliding surfaces in Fig. 10 are quite similar to those of YG with rough surfaces, reported in Yao et al. (2013b, Fig. 5). But the textures are quite variable in different runs and it is nearly impossible to find the differences in the deformation textures, reflecting the difference in surface roughness of the sliding surface.

\section{Discussion}

The main purposes of this paper are to describe a rotary-shear LHV friction apparatus installed at IGCEA in detail, and to report results from velocity-jump tests from $1.4 \mathrm{~mm} / \mathrm{s}$ to $1.4 \mathrm{~m} / \mathrm{s}$ in slip rates on the yellowish gouge (YG) from the Pingxi fault zone, one of the best studied fault gouges in relation to the 2008 Wenchuan earthquake. The second purpose was intended to highlight the difficulty in conducting velocity step tests in the high-velocity regime in order to separate the instantaneous and transient responses upon a step change in velocity. This is critical to test whether the (a)
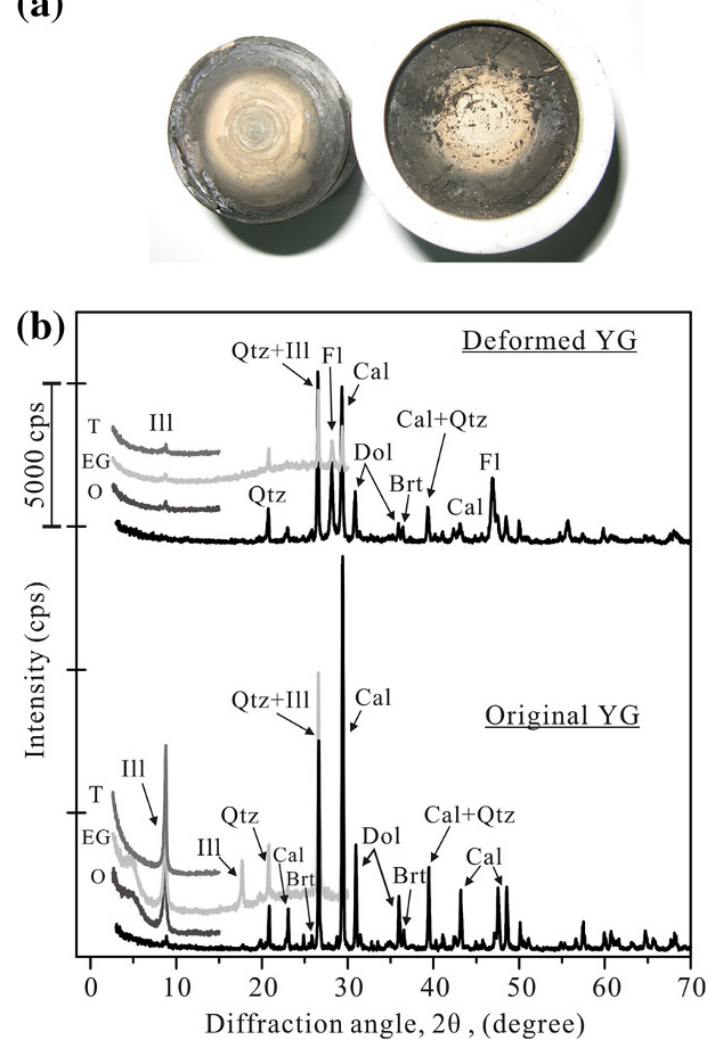

Fig. 9 a Photographs of typical deformed yellowish gouge (YG) sample after the rotary specimen on the left side were separated from the stationary specimen (gabbro with a smooth sliding surface) on the right side (run LHV076; a normal stress of $1.7 \mathrm{MPa}$ and a slip rate of $1.4 \mathrm{~m} / \mathrm{s}$ ). b XRD diagrams for undeformed YG (bottom) and deformed YG (top; the samples for XRD measurement were collected from the outer $2 / 3$ area). O, EG, and T correspond to the XRD profiles for oriented, ethylene-glycol treated and thermally treated samples for clay mineral analysis, respectively. Mineral abbreviations in the figure are Cal calcite, $Q t z$ quartz, Dol dolomite, Ill illite, Smc smectite, Brt barite, and $F l$ fluorite

framework of rate-and-state constitutive law holds or not in the high-velocity regime. We took this opportunity to summarize and compare the capabilities of nineteen rotary-shear friction apparatuses that have high-velocity capabilities (Fig. 1; Table 1) and to summarize major outcomes using the apparatuses. For the sake of convenience, we classified slip rate into three regimes; that is, low velocity below $10^{-7} \mathrm{~m} / \mathrm{s}(32 \mathrm{~mm} / \mathrm{a})$, intermediate velocity between $10^{-7}$ and $10^{-4} \mathrm{~m} / \mathrm{s}$, and high velocity above $10^{-4} \mathrm{~m} / \mathrm{s}$. Then there are six high-velocity (HV) friction apparatuses, five IHV apparatuses, and eight LHV apparatuses currently available (Table 1).

$\mathrm{HV}$ apparatuses use either a direct connection between the motor and the specimen or a gear/belt assembly to reduce the motor speed slightly, and are mostly capable of producing seismic slip rates on the order of $1 \mathrm{~m} / \mathrm{s}$. A representative apparatus is the first HV machine built by Shimamoto that has been used in a variety of problems. IHV apparatuses are 


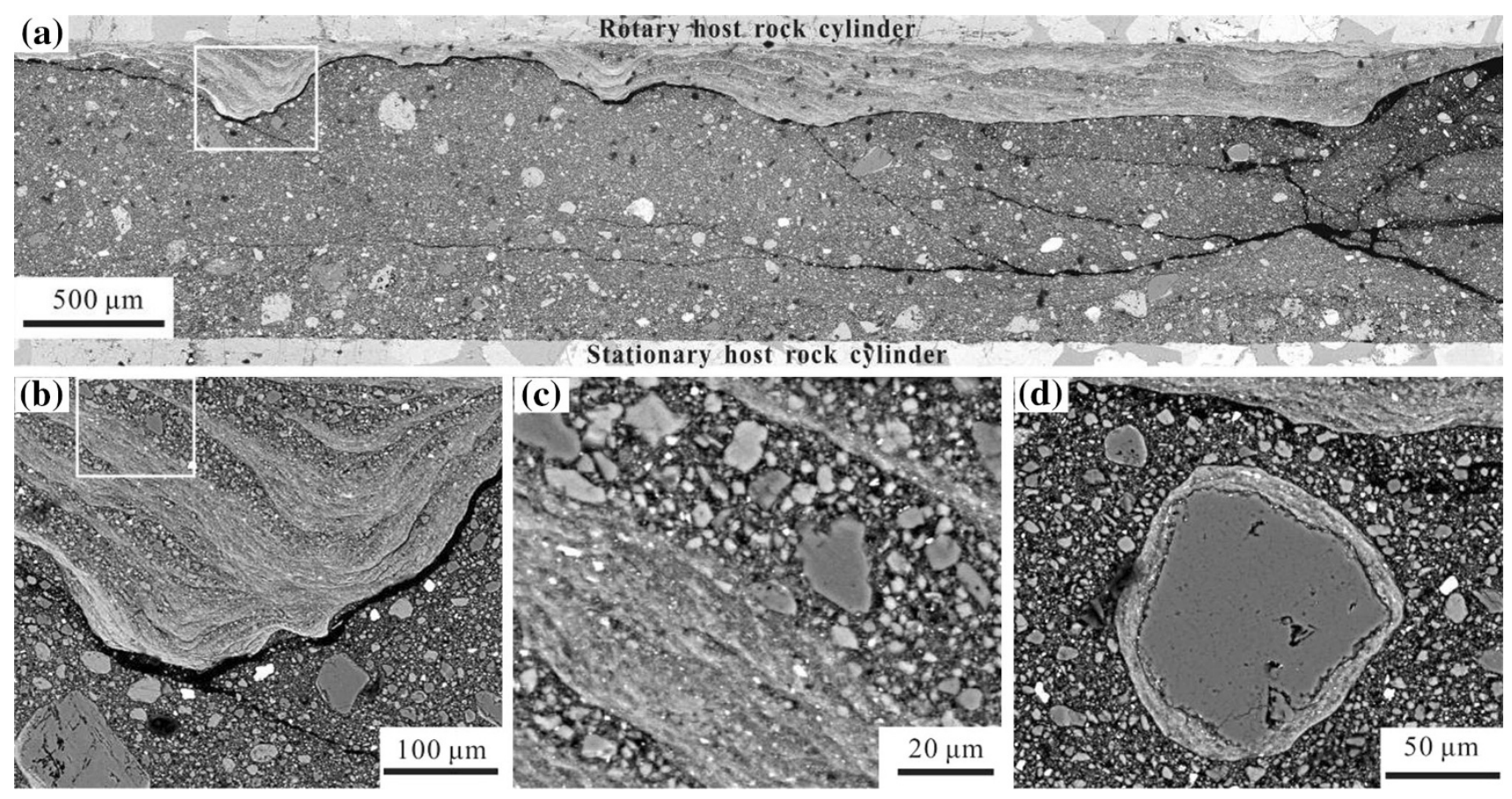

Fig. 10 Back-scattered electron images of the yellowish gouge (YG) with gabbro specimens having smooth sliding surfaces deformed at a normal stress of $0.8 \mathrm{MPa}$ and a slip rate of $1.40 \mathrm{~m} / \mathrm{s}$ (LHV019). a Microstructures of deformed gouge zone on a thin-section parallel to the specimen axis and going through the center (about two-third of the gouge adjacent to the rotary side). The left end of the photograph is $15 \mathrm{~mm}$ from the center, and the right end is on the outer side. Slip zones formed adjacent to the rotary host rock at the top. b A close-up photomicrograph of the overlapping slipping zones in the framed portion in $\mathbf{a}, \mathbf{c}$ a further close-up of a slip zone in the framed portion in $\mathbf{b}$, and d a clay-clast aggregate consisting of ultra-fine calcite grains and clay minerals around a quartz clast in the center. All SEM images were taken with a field-emission environmental SEM (Quanta200F, FEI Ltd.) at the accelerating voltage of $20 \mathrm{kV}$ at the Microstructure Laboratory for Energy Materials, China University of Petroleum

usually equipped with a direct line and one more gear/belt system to reduce a slip rate by two to three orders of magnitude. Two torsion/compression apparatuses with servohydraulic actuators have similar capabilities in producing intermediate to high-velocities. Those apparatuses are capable of studying intermediate velocity regime, still poorly explored area, to seismic fault motion at high velocities. However, studying frictional properties at low slip rate such as rate-and-state friction are often difficult with those apparatuses. LHV apparatuses, on the other hand, are equipped with three or four velocity ranges in gear/belt systems that can cover the plate velocity to seismic slip rates. Plate to seismic velocities have to be covered in order to study the earthquake nucleation to seismic rupture processes, and it was a natural choice to cover slip rates of $10^{-9}$ to about $2 \mathrm{~m} / \mathrm{s}$ in designing our present apparatus at IGCEA (Fig. 2). Seven out of eight LHV apparatuses were designed by the second author (TS), and the four apparatuses (Padova, NCU-Taiwan, Durham and Liverpool) are smaller versions of our apparatus reported here. Complete changes in frictional properties from plate to seismic velocities have not been studied systematically as yet, but those LHV apparatuses are available for such comprehensive studies.
Extensive review of published work with high-velocity apparatuses in Sect. 2.2 elucidates that most high-velocity experiments have been conducted dry under room humidity conditions, although high-velocity friction experiments with controlled pore pressure are reported recently (Violay et al. 2013, 2014; Oohashi et al. 2014). Development of pressure vessel for high-velocity friction experiments is not easy, and the most important concept for building our LHV apparatus was to make a fairly large specimen chamber where different specimen assemblies can be developed and set up easily. We report here a pressure vessel for pressures to $70 \mathrm{MPa}$ at room temperature and preliminary experiments with the vessel (Figs. 6, 7), and the vessel is ready for systematic LHV experiments with controlled pore pressures. We have just built a hydrothermal pressure vessel with pressures to $70 \mathrm{MPa}$ and temperatures $500{ }^{\circ} \mathrm{C}$ with an external furnace $\left(470{ }^{\circ} \mathrm{C}\right.$ was achieved during a test of the vessel). This will be used in friction experiments very soon. The concept of making a specimen chamber as a common platform for developing purpose-oriented specimen assemblies was highly successful although the space for the specimen assembly (currently $482 \mathrm{~mm}$ ) was little narrower in making high-temperature pressure vessels. 
Another capability of our apparatus that we seriously concerned was a velocity step capability including highvelocity regime to separate the instantaneous and transient responses upon a step change in slip rate. This capability is needed to check if the framework of the rate-and-state friction law (Dieterich 1978, 1979; Ruina 1983) holds or not at high velocities. Our apparatus has three means to change velocity; (1) servomotor speed which can produce a change in velocity by three order of magnitude in $0.1-0.2 \mathrm{~s}$, (2) three velocity ranges of gear/belt lines which can be changed with electromagnetic clutches without stopping the servomotor (1,000-fold changes in velocity between high and intermediate lines and between intermediate and slow lines in 0.1-0.2 s), and (3) a cam clutch system that allows fivefold reduction and then fivefold increase in velocity mechanically with high-velocity gear/ belt line. A torque was lost almost completely when slip rate was reduced by 1,000 times by changing the intermediate to slow lines and the fast to intermediate lines (Fig. 5). But other ways of changing velocity seem to work fine. In particular, an arbitrary slip history can be imposed by using a function generator. We plan to install a servocontrol system for controlling the servomotor by using feedback signals such as torque and displacement in the near future.

We presented results from velocity-jump tests from $1.4 \mathrm{~mm} / \mathrm{s}$ to $1.4 \mathrm{~m} / \mathrm{s}$ on the yellowish gouge (YG) from the Pingxi fault zone that caused the 2008 Wenchuan earthquake (Yao et al. 2013a), as an example of using the velocity jump capability. Results with smooth $(100 \mu \mathrm{m})$ sliding surfaces of Indian gabbro revealed an abrupt increase in friction followed by marked slip-weakening, similar to the rate-andstate frictional behaviors at low slip rates (Fig. 8a). However, the same gouge with rough $(180 \mu \mathrm{m})$ sliding surfaces did not exhibit an abrupt increase in friction coefficient (Fig. 8b). If an instantaneous response of friction upon a step change in velocity reflects a gouge property, it is strange that the abrupt increase in friction disappears by changing the surface roughness of the host rock slightly. Our elaborate discussion on Fig. 8 in the last section showed that the contrasting behaviors with smooth and rough sliding surfaces can be explained by changes in friction at $1.4 \mathrm{~mm} / \mathrm{s}$ to that at $1.4 \mathrm{~m} / \mathrm{s}$. We are inclined to believe this explanation at present. However, we point out a difficulty in delineating the instantaneous response in friction upon a step change through velocity-jump tests below. The slip rate increased nearly linearly for $0.15 \mathrm{~s}$ during the velocity jump from $1.4 \mathrm{~mm} / \mathrm{s}$ to $1.4 \mathrm{~m} / \mathrm{s}$ (Fig. $8 \mathrm{a}$, inset diagram), so that the displacement during this abrupt velocity increase is about $0.11 \mathrm{~m}$. This displacement is far larger than the typical evolution distance on the order of $10^{-5}-10^{-4} \mathrm{~m}$ of the rate and state constitutive laws (e.g., Noda and Shimamoto 2009; references therein). Only about $5 \mathrm{~ms}$ is needed to reach $10^{-4}$ m during our velocity jump tests, and any changes in friction in such a short duration cannot be detected with our cantilever-type torque gauge with characteristic frequency of about $200 \mathrm{~Hz}$ because the heavy loading column cannot be accelerated quickly. Thus, further advancement in separating the instantaneous and transient terms during velocity stepping tests in high-velocity regime awaits for development of quick and sensitive torque gauge, very close to the specimens. Also, smaller steps in velocity will be useful to delineate the instantaneous response because the slip during the velocity change will be kept small. A systematic work with our cam clutch system would be of interest for that purpose.

Conducting high-velocity friction experiments at high normal stresses on the order of $100 \mathrm{MPa}$ is a barrier to realize the "dream" machine to reproduce seismic fault motion at great depths. Making metal sample holders (Smith et al. 2013; Balsimo et al. 2014) would be an obvious way toward achieving this goal, but care must be taken into the difference in thermal conductivity between rocks and metals. A. Niemeijer informed us with a Ti-Al$\mathrm{V}$ alloy which has almost as low thermal conductivity as rocks, and indeed we confirmed that gouge with specimens of this material exhibited similar behavior to the gouge with gabbro specimens (to be reported elsewhere). This material will expand high-velocity experiments to much larger normal stresses (we made specimen holders with this material for a new pressure vessel). From the perspectives of designing friction apparatuses, however, it should be kept in mind that a thin and long loading column, used in most apparatuses, becomes unstable when a very large axial load is applied. Specimen assemblies for very high normal stresses have to be designed from a different concept, which may lead to the fourth generation of highvelocity friction apparatus.

\section{Conclusions}

This paper reviewed nineteen rotary-shear friction apparatuses with high-velocity capabilities and summarized major research outcomes using those apparatuses. Then the paper describes a LHV friction apparatus at Institute of Geology, China Earthquake Administration, and reports representative results from high-velocity friction experiments using the apparatus. The main conclusions are summarized as follows.

(1) The apparatus consists of a $22 \mathrm{~kW}$ servomotor, a gear/belt system with three speed lines, a large specimen chamber to set up different specimen assemblies, axial loading device (an air actuator of $10 \mathrm{kN}$ or a hydraulic actuator of $100 \mathrm{kN}$ ), and 
measurement instruments. Friction experiments can be performed at plate to seismic velocities $\left(10^{-9}\right.$ to $2 \mathrm{~m} / \mathrm{s}$ ) and at normal stresses to a range of $50 \mathrm{MPa}$ using cylindrical specimens of 40 or $25 \mathrm{~mm}$ in diameter. A step change in velocity up to six orders of magnitude in $0.1-0.2 \mathrm{~s}$ can be achieved by combining the speed control of servomotor, and changes in gear/belt lines by using five electromagnetic clutches. However, the shear stress is released nearly completely during 1,000-fold velocity reductions with the gear/belt lines. But 1,000-fold velocity increase with the gear/belt system, fivefold decrease and increase in velocity with a cam clutch system in the high-velocity line, and velocity changes up to three orders of magnitude by changing motor speed can be used to delineate the instantaneous and transient responses in friction to a velocity step. The apparatus will be useful in studying frictional properties associated with the nucleation to rupture propagation of earthquakes.

(2) The most unique part of this apparatus is the specimen chamber $(697 \mathrm{~mm}$ high, $250 \mathrm{~mm}$ wide and $55 \mathrm{~mm}$ deep) where any specimen assembly can be set up easily as long as the assembly can be inserted into a space of $482 \mathrm{~mm}$. We built a standard specimen assembly without a pressure vessel and two pressure vessels. The paper describes a pressure vessel for room temperature with pore pressure to $70 \mathrm{MPa}$ and reports preliminary experimental results on Shanxi dolerite. The second vessel just made allows pressures to $70 \mathrm{MPa}$ and temperatures to $500{ }^{\circ} \mathrm{C}$ with an external furnace, and friction experiments with super-critical water will become possible soon. A specimen chamber as a common platform is very useful for developing purpose-oriented specimen assemblies.

(3) Velocity-jump tests from $1.4 \mathrm{~mm} / \mathrm{s}$ to $1.4 \mathrm{~m} / \mathrm{s}$ in about $0.15 \mathrm{~s}$ were conducted on the yellowish gouge (YG) from the Pingxi fault zone that caused the 2008 Wenchuan earthquake, to see if the framework of rate-and-state constitutive law holds at seismic slip rates or not. The observed behaviors were somewhat controversial. YG with smooth sliding surface of host rock gabbro exhibits nearly instantaneous response followed by slip weakening, in a similar manner as recognized in rate and state frictional behaviors at low slip rates. However, the same gouge with rough sliding surface did not show any instantaneous response. The results can be explained by changes in friction at $1.4 \mathrm{~mm} / \mathrm{s}$ to that at $1.4 \mathrm{~m} / \mathrm{s}$, rather than an instantaneous response upon a step change in velocity. A smaller step is appropriate to delineate the instantaneous and transient responses, and the response of our cantilever-type torque gauge (about $200 \mathrm{~Hz}$ now) has to be improved to capture the true instantaneous response at high slip rates.

Acknowledgments We thank engineers of Marui Co. Ltd., Osaka, Japan for their enthusiasm in building the LHVR-Beijing used in this study, and members of the State Key Laboratory of Earthquake Dynamics, Institute of Geology, China Earthquake Administration for many useful discussions and suggestions. We also sincerely thank an anonymous reviewer and Zonghu Liao for reviewing our manuscript, J.-J. Dong for useful comments on our manuscript, and G. Di Toro, J. G. Spray, A. Tsutsumi, Ze'ev Reches, D. L. Goldsby and K. Okazaki for useful information on the friction apparatuses listed in Table 1. This work was supported by State Key Laboratory of Earthquake Dynamics (Project No. LED2014A06 \& LED2010A05).

\section{Appendix: Friction of the Teflon sleeve and its correction for measured shear stress}

We conducted all gouge experiments with Teflon sleeves (right photograph in Fig. 9a) because gouge is lost almost instantly without it upon the onset of a run. However, a Teflon sleeve imposes an extra torque due to its friction at the moving-block interface and often decomposes during friction experiments emitting highly reactive fluorine gas (see a comprehensive review by Sawai et al. 2012, Appendix). We made correction for Teflon friction during constant slip-rate tests and velocity jump tests in the following manners.

For constant slip-rate tests, we used a method slightly modified from that of Togo et al. (2011). An increase in measured shear stress due to the friction between a Teflon sleeve and specimens (simply referred to "Teflon friction" hereafter) can be estimated from the intercepts of shear stress versus normal stress curves (Sawai et al. 2012, Appendix). Togo et al. (2011) assume that Teflon friction increases linearly from zero at the onset of an experiment to the peak Teflon friction and then decreases exponentially to steady-state Teflon friction with the same slip-weakening distance as that determined for each friction experiment. We slightly modified this estimate by assuming that an increase in Teflon friction is proportional to the increase in measured shear stress based on seven runs conducted on gabbro host-rock specimens, with sliding surfaces about $1 \mathrm{~mm}$ apart, and with a Teflon sleeve under no axial load. Results in Fig. 11 indicate that an increase in Teflon friction is not linear up to the peak friction and that the friction is approximated better by an increase in proportion to an increase in rock friction (cf. the initial loading parts). We assumed that displacements for the peak and steady-state Teflon friction are the same as those of gouge friction although displacement at the peak Teflon friction tends to be greater than that for gouge friction (cf. Fig. 11). Teflon 


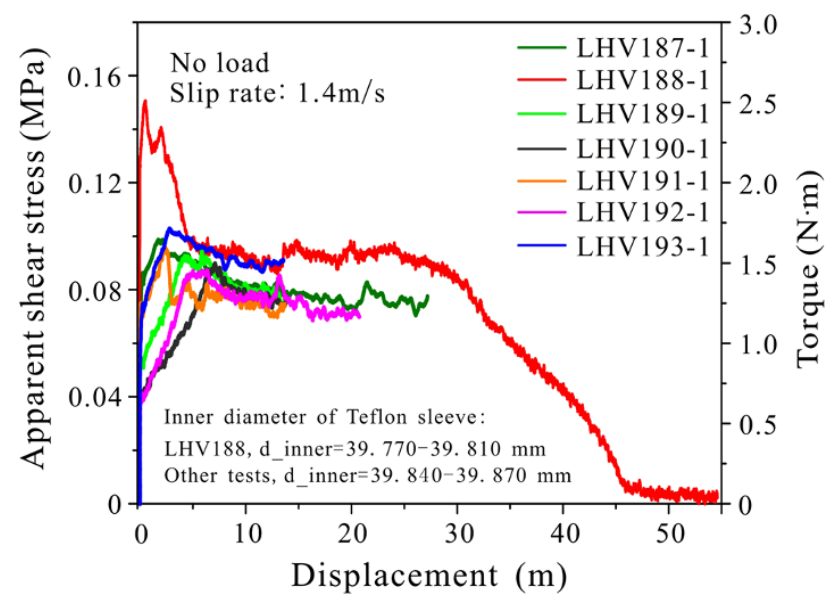

Fig. 11 Measured torque plotted against displacement for gabbro specimens with a Teflon sleeve rotated at a slip rate of $1.4 \mathrm{~m} / \mathrm{s}$ and under no axial load. A Teflon sleeve with a slightly smaller inner diameter was used for run LHV188 than in other cases (see the red curve and the inner diameter, $\mathrm{d}$ _inner, in the diagram) and the Teflon friction was higher for this case

sleeve for a run LHV188 was made tighter with its inner diameter smaller than the specimen diameter by about $190 \mu \mathrm{m}$, thereby imposing higher pressure for the sleeve/ Teflon interface, than for the other Teflon sleeves made smaller by about $120-130 \mu \mathrm{m}$. Tight Teflon sleeve exhibits higher initial friction and continued reduction of friction at large displacements than typical Teflon sleeves used in the present study (red curve in Fig. 11). Six Teflon sleeves have peak friction of $0.085-0.105 \mathrm{MPa}$ and steady-state friction of around $0.070-0.090 \mathrm{MPa}$ (Fig. 11). Those values are consistent with Teflon friction determined from the intercepts, $0.091 \pm 0.023$ and $0.077 \pm 0.013 \mathrm{MPa}$ for the yellowish gouge (YG) at the peak and steady-state friction, respectively (Yao et al. 2013a, Fig. 6c). However, the Teflon friction in gouge experiments may depends on gouge type because at least some gouge particles may be squeezed into the Teflon-specimen interface. Yao et al. (2013a, Fig. 6b) reports somewhat smaller intercepts, $0.051 \pm 0.015$ and $0.054 \pm 0.018 \mathrm{MPa}$ for the grayblackish gouge from the same Pingxi fault zone at the peak and steady-state friction, respectively. Moreover, the intercepts depends on workers as compiled by Sawai et al. (2012, Table A1). It is recommended to study the effects of normal stress in each gouge experiment to determine the intercepts for correcting the Teflon friction.

A Teflon sleeve run similar to the velocity jump tests (Fig. 8) was performed on a pair of gabbro specimens (separated by about $1 \mathrm{~mm}$ ) with a Teflon sleeve and no axial load in order to measure how Teflon friction evolves during this type of test (Fig. 12a). During the pre-sliding for $30 \mathrm{~s}$ at a slip rate of $1.4 \mathrm{~mm} / \mathrm{s}$, the Teflon friction abruptly increases to $0.068 \mathrm{MPa}$ at the onset of slip and
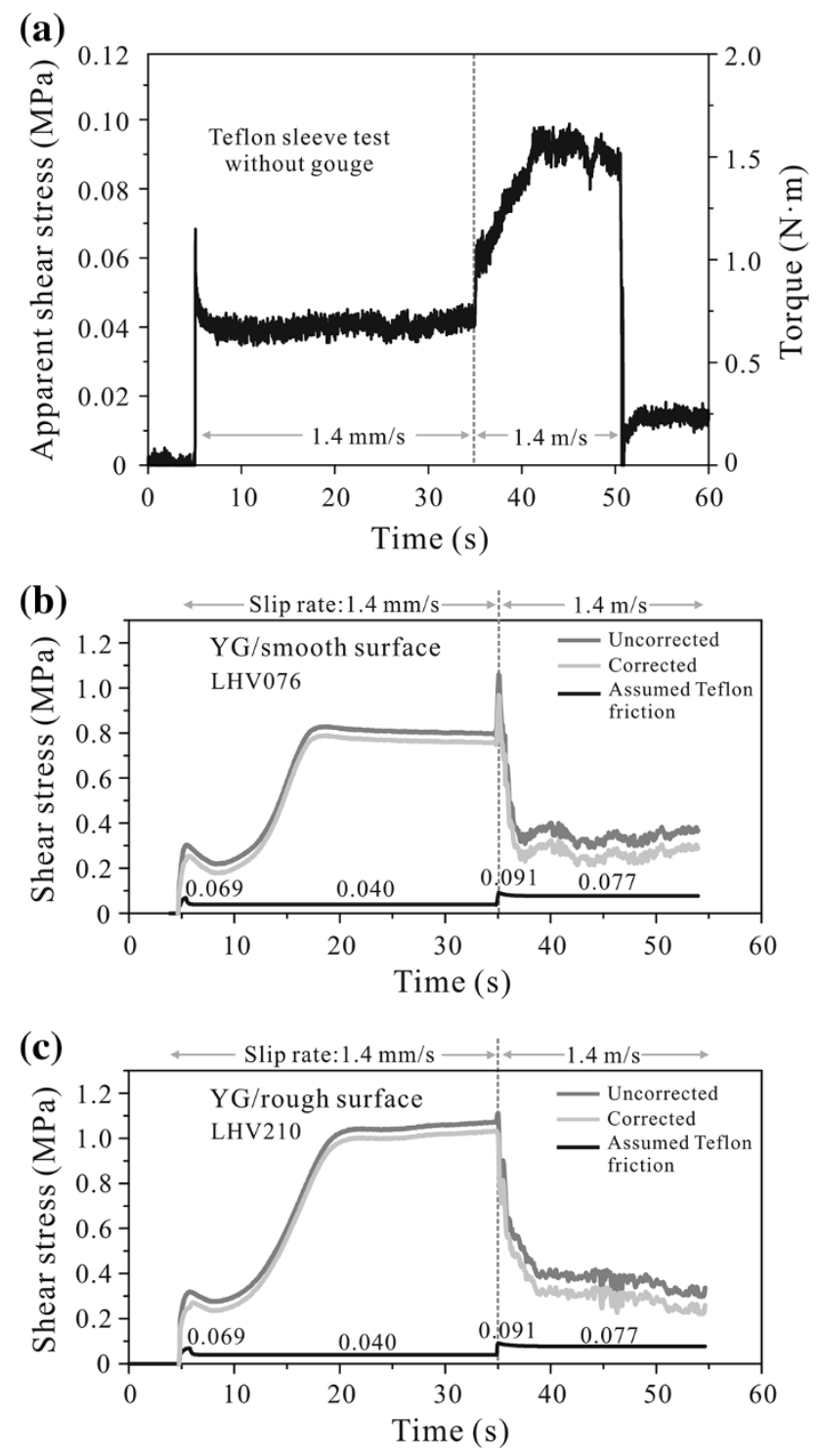

Fig. 12 A method for correcting measured shear stress for the Teflon friction for velocity-jump tests on the yellowish gouge (YG). a Change in torque and apparent shear stress during a velocity-jump test on a pair of gabbro specimens with a Teflon sleeve under no axial load, at slip rates as shown in the figure. Gabbro specimens were separated by about $1.0 \mathrm{~mm}$ to avoid rock-on-rock friction. b, c Original data for shear stress (uncorrected) in dark-gray curves, assumed Teflon friction in black curves at the bottom based on the measured Teflon friction as shown in a, and corrected shear-stress changes in light-gray curves, all plotted against time. b, c Two typical experimental results for YG with smooth and rough sliding surfaces of host rocks, respectively

decays to about $0.04 \mathrm{MPa}$ within a displacement of several millimeters. The torque due to the Teflon-specimen friction is converted to the shear stress on the sliding surface, and we called it "apparent shear stress" on the vertical axis of Fig. 12a. The peak Teflon friction at $1.4 \mathrm{~mm} / \mathrm{s}$ $(0.069 \mathrm{MPa})$ is somewhat smaller than that at high slip rates (0.085-0.105 MPa; Fig. 11). Thus we idealized the 
Teflon friction by an increase in Teflon friction in proportion to the gouge friction to the peak value of $0.069 \mathrm{MPa}$, followed by an exponential decay to the steady-state value of $0.04 \mathrm{MPa}$ with characteristic slip $d_{\mathrm{c}}$ of $0.16 \mathrm{~mm}$. Thus the post-peak Teflon friction is given by $\left[0.040+(0.069-0.040) \exp \left(-d / d_{\mathrm{c}}\right)\right]$. During the subsequent slip at a slip rate of $1.4 \mathrm{~m} / \mathrm{s}$, Teflon friction increases abruptly by about $0.020 \mathrm{MPa}$, then gradually increases to about $0.092 \mathrm{MPa}$ at the peak and decreases with further slip (see the curve after velocity jump in Fig. 12a). This value of Teflon peak friction and overall change in Teflon friction is very similar to the Teflon friction during constant velocity tests at high slip rates (Fig. 11). Thus we used the same procedure for correcting the Teflon friction during constant velocity tests, as explained above.

Teflon friction thus idealized during pre-sliding tests (velocity jump tests) is shown as black solid lines in Fig. 12b and c. The original experimental data for shear stress and the shear stress corrected for the Teflon friction are shown as dark and light-gray curves, respectively, in Fig. 12b and c. Yellowish gouge (YG) with smooth sliding surface exhibits nearly instantaneous increase in friction upon the velocity jump, and this increase in friction remain even after the correction of the Teflon friction (Fig. 12b). On the other hand, YG with rough sliding surface shows a small amount of instantaneous increase in friction at the velocity jump, but this mostly disappears with the correction for the Teflon friction (Fig. 12c).

\section{References}

Balsimo F, Aldega L, De Paola N, Faoro I, Storti F (2014) The signature and mechanics of earthquake ruptures along shallow creeping faults in poorly lithified sediments. Geology 42(5):435-438

Beeler NM, Tullis TE, Blanpied ML, Weeks JD (1996) Frictional behavior of large displacement experimental faults. J Geophys Res 101:8697-8715

Blanpied ML, Tullis TE, Weeks JD (1987) Frictional behavior of granite at low and high sliding velocities. Geophys Res Lett 14:554-557

Boutareaud S, Boullier A-M, Andréani M, Calugaru D-G, Beck P, Song SR, Shimamoto T (2010) Clay clast aggregates in gouges: new textural evidence for seismic faulting. J Geophys Res Solid Earth 115(B2):B02408. doi:10.1029/2008JB006254

Brantut N, Schubnel A, Rouzaud JN, Brunet F, Shimamoto T (2008) High-velocity frictional properties of a clay-bearing fault gouge and implications for earthquake mechanics. J Geophys Res Solid Earth 113:B10401. doi:10.1029/2007JB005551

Brantut N, Han R, Shimamoto T, Findling N, Schubnel A (2011) Fast slip with inhibited temperature rise due to mineral dehydration: evidence from experiment on gypsum. Geology 39:59-62

Brown KM, Fialko Y (2012) 'Melt welt' mechanism of extreme weakening of gabbro at seismic slip rates. Nature 488:638-641
Chang JC, Lockner DA, Reches Z (2012) Rapid acceleration leads to rapid weakening in earthquake-like laboratory experiments. Science 338:101-105

Chen J, Yang X, Yao L, Ma S, Shimamoto T (2013a) Frictional and transport properties of the 2008 Wenchuan earthquake fault zone: implications for coseismic slip-weakening mechanisms. Tectonophysics 603:237-256

Chen X, Madden AS, Bickmore BR, Reches Z (2013b) Dynamic weakening by nanoscale smoothing during high-velocity fault slip. Geology 41:739-742

Chen J, Yang X, Duan Q, Shimamoto T, Spiers CJ (2013c) Importance of thermochemical pressurization in the dynamic weakening of the Longmenshan Fault during the 2008 Wenchuan earthquake: inferences from experiments and modeling. J Geophys Res 118(8):4145-4169

De Paola N, Hirose T, Mitchell T, Di Toro G, Viti C, Shimamoto T (2011) Fault lubrication and earthquake propagation in thermally unstable rocks. Geology 39:35-38

Del Gaudio P, Di Toro G, Han R, Hirose T, Nielsen S, Shimamoto T (2009) Frictional melting of peridotite and seismic slip. J Geophys Res 114:B06306. doi:10.1029/2008JB005990

Di Toro G, Goldsby DL, Tullis TE (2004) Friction falls towards zero in quartz rock as slip velocity approaches seismic rates. Nature 427:436-439

Di Toro G, Hirose T, Nielsen S, Pennacchioni G, Shimamoto T (2006) Natural and experimental evidence of melt lubrication of faults during earthquakes. Science 311:647-649

Di Toro G, Niemeijer A, Tripoli A, Nielsen S, Di Felice F, Scarlato P, Spada G, Alessandroni R, Romeo G, Di Stefano G, Smith S, Spagnuolo E, Mariano S (2010) From field geology to earthquake simulation: a new state-of-the-art tool to investigate rock friction during the seismic cycle (SHIVA). Rend Fis Acc Lincei 21(Suppl 1):S95-S114

Di Toro G, Han R, Hirose T, De Paola N, Nielsen S, Mizoguchi K, Ferri F, Cocco M, Shimamoto T (2011) Fault lubrication during earthquakes. Nature 471:494-498

Dieterich JH (1978) Time-dependent friction and the mechanics of stick-slip. Pure Appl Geophys 116:790-806

Dieterich JH (1979) Modeling of rock friction: 1. Experimental results and constitutive equations. J Geophys Res 84:2161-2168

Dieterich JH (1981) Constitutive properties of faults with simulated gouge. Geophys Monogr AGU 24:103-120

Faulkner DR, Mitchell TM, Behnsen J, Hirose T, Shimamoto T (2011) Stuck in the mud? Earthquake nucleation and propagation through accretionary forearcs. Geophys Res Lett 38:L18303. doi:10.1029/2011GL048552

Ferri F, Di Toro G, Hirose T, Shimamoto T (2010) Evidence of thermal pressurization in high-velocity friction experiments on smectite-rich gouges. Terra Nova 22:347-353

Ferri F, Di Toro G, Hirose T, Han R, Noda H, Shimamoto T, Quaresimin M, de Rossi N (2011) Low- to high-velocity frictional properties of the clay-rich gouges from the slipping zone of the 1963 Vaiont slide, Northern Italy. J Geophys Res 116:B09208. doi:10.1029/2011JB008338

Fondriest M, Smith SAF, Candela T, Nielsen SB, Mair K, Toro Di (2013) Mirror-like faults and power dissipation during earthquakes. Geology 41:1175-1178

Fukuchi T, Mizoguchi K, Shimamoto T (2005) Ferrimagnetic resonance signal produced by frictional heating: a new indicator of paleoseismicity. J Geophys Res 110:B12404. doi:10.1029/ 2004JB003485

Fukuyama E, Mizoguchi K (2010) Constitutive parameters for earthquake rupture dynamics based on high-velocity friction tests with variable slip rate. Int J Fract 163:15-26 
Goldsby DL, Tullis TE (2002) Low frictional strength of quartz rocks at subseismic slip rates. Geophys Res Lett 29:1844. doi:10.1029/ 2002GL015240

Goldsby DL, Tullis TE (2011) Flash heating leads to low frictional strength of crustal rocks at earthquake slip rates. Science $334: 216-218$

Han R, Hirose T (2012) Clay-clast aggregates in fault gouge: an unequivocal indicator of seismic faulting at shallow depths? J Struct Geol 43:92-99

Han R, Shimamoto T, Hirose T, Ree J-H, Ando J (2007a) Ultralow friction of carbonate faults caused by thermal decomposition. Science 316:878-881

Han R, Shimamoto T, Ando J, Ree J-H (2007b) Seismic slip record in carbonate-bearing fault zones: An insight from high-velocity friction experiments on siderite gouge. Geology 35:1131-1134

Han R, Hirose T, Shimamoto T (2010) Strong velocity weakening and powder lubrication of simulated carbonate faults at seismic slip rates. J Geophys Res 115:B03412. doi:10.1029/2008JB006136

Han R, Hirose T, Shimamoto T, Lee Y, Ando J (2011) Granular nanoparticles lubricate faults during seismic slip. Geology 39:599-602

Hayashi N, Tsutsumi A (2010) Deformation textures and mechanical behavior of a hydrated amorphous silica formed along an experimentally produced fault in chert. Geophys Res Lett 37:L12305. doi:10.1029/2010GL042943

Hirose T, Bystricky M (2007) Extreme dynamic weakening of faults during dehydration by coseismic shear heating. Geophys Res Lett 34:L14311

Hirose T, Shimamoto $\mathrm{T}$ (2005) Growth of molten zone as a mechanism of slip weakening of simulated faults in gabbro during frictional melting. J Geophys Res 110:B05202. doi:10. 1029/2004JB003207

Hirose T, Kawagucci S, Suzuki K (2011) Mechanoradical $\mathrm{H}_{2}$ generation during simulated faulting: implications for an earthquake-driven subsurface biosphere. Geophys Res Lett 38:L17303. doi:10.1029/2011GL048850

Hirose T, Mizoguchi K, Shimamoto T (2012) Wear processes in rocks at slow to high slip rates. J Struct Geol 38:102-116

Hou L, Ma S, Shimamoto T, Chen J, Yao L, Yang X, Okimura Y (2012) Internal structures and high-velocity frictional properties of a bedding-parallel carbonate fault at Xiaojiaqiao outcrop activated by the 2008 Wenchuan earthquake. Earthq Sci 25:197-217

Kawamoto E, Shimamoto T (1997) Mechanical behavior of halite and calcite shear zones from brittle to fully-plastic deformation and a revised fault model. In: Proceedings of 30th International Geological Congress, Beijing, vol 14. VSP Press, Utrecht, pp 89-105

Kendrick JE, Lavallée Y, Hirose T, Di Toro G, Hornby AJ, De Angelis S, Dingwell DB (2014) Volcanic drumbeat seismicity caused by stick-slip motion and magmatic frictional melting. Nat Geosci 7:438-442

Kim W-K, Ree J-H, Han R, Shimamoto T (2010) Experimental evidence for the simultaneous formation of pseudotachylyte and mylonite in the brittle regime. Geology 38:1143-1146

Kitajima H, Chester JS, Chester FM, Shimamoto T (2010) High-speed friction of disaggregated ultracataclasite in rotary shear: Characterization of frictional heating, mechanical behavior, and microstructure evolution. J Geophys Res 115:B08408. doi:10. 1029/2009JB007038

Kitajima H, Chester FM, Chester JS, Shimamoto T (2011) Dynamic weakening of gouge layers in high-speed shear experiments: assessment of temperature-dependent friction, thermal pressurization, and flash heating. J Geophys Res 116:B08309. doi:10. 1029/2009JB007879
Kitamura M, Mukoyoshi H, Fulton PM, Hirose T (2012) Coal maturation by frictional heat during rapid fault slip. Geophys Res Lett 39:L16302. doi:10.1029/2012GL052316

Kohli AH, Goldsby DL, Hirth G, Tullis TE (2011) Flash weakening of serpentinite at near-seismic slip rates. J Geophys Res 116:B03202. doi:10.1029/2010JB007833

Kuo L, Li H, Smith SAF, Di Toro G, Suppe J, Song S-R, Nielsen S, Sheu H-S, Si J (2014) Gouge graphitization and dynamic fault weakening during the $2008 M_{\mathrm{w}} 7.9$ Wenchuan earthquake. Geology 42:47-50

Lavallée Y, Mitchell TM, Heap MJ, Vasseur J, Hess K-U, Hirose T, Dingwell DB (2012) Experimental generation of volcanic pseudotachylytes: constraining rheology. J Struct Geol 38:222-233

Lavallée Y, Hirose T, Kendrick JE, Angelis SD, Petrakova L, Hornby AJ, Dingwell DB (2014) A frictional law for volcanic ash gouge. Earth Planet Sci Lett 400:177-183

Lim SC, Ashby MF, Brunton JH (1989) The effects of sliding conditions on the dry friction of metals. Acta Metall 37:767-772

Lin A, Shimamoto T (1998) Selective melting processes as inferred from experimentally-generated pseudotachylytes. J Asian Earth Sci 16:533-545

Lin A, Takano S, Hirono T, Kanagawa K (2013) Coseismic dehydration of serpentinite: evidence from high-velocity friction experiments. Chem Geol 344:50-62

Marone C (1998) Laboratory-derived friction laws and their application to seismic faulting. Annu Rev Earth Planet Sci 26:643-696

Mizoguchi K, Fukuyama E (2010) Laboratory measurements of rock friction at subseismic slip velocities. Int J Rock Mech Min Sci 47:1363-1371

Mizoguchi K, Hirose T, Shimamoto T, Fukuyama E (2007) Reconstruction of seismic faulting by high-velocity friction experiments: an example of the 1995 Kobe earthquake. Geophys Res Lett 34:L01308

Mizoguchi K, Hirose T, Shimamoto T, Fukuyama E (2009a) Highvelocity frictional behavior and microstructure evolution of fault gouge obtained from Nojima fault, southwest Japan. Tectonophysics 471:285-296

Mizoguchi K, Hirose T, Shimamoto T, Fukuyama E (2009b) Fault heals rapidly after dynamic weakening. Bull Seismol Soc Am 99:3470-3474. doi:10.1785/0120080325

Nakatani M (2001) Conceptual and physical clarification of rate and state friction: frictional sliding as a thermally activated rheology. J Geophys Res 106:13347-13380

Namiki Y, Tsutsumi A, Ujiie K, Kameda J (2014) Frictional properties of sediments entering the Costa Rica subduction zone offshore the Osa Peninsula: implications for fault slip in shallow subduction zones. Earth Planets Space 66:72. doi:10.1186/1880-5981-66-72

Nielsen S, Di Toro G, Hirose T, Shimamoto T (2008) Frictional melt and seismic slip. J Geophys Res 113:B01308. doi:10.1029/ 2007JB005122

Niemeijer A, Di Toro G, Nielsen S, Di Felice F (2011) Frictional melting of gabbro under extreme experimental conditions of normal stress, acceleration, and sliding velocity. J Geophys Res 116:B07404. doi:10.1029/2010JB008181

Noda H, Shimamoto T (2009) Constitutive properties of clayey fault gouge from the Hanaore fault zone, southwest Japan. J Geophys Res 114:B04409. doi:10.1029/2008JB005683

Noda H, Kanagawa K, Hirose T, Inoue A (2011) Frictional experiments of dolerite at intermediate slip rates with controlled temperature: rate weakening or temperature weakening? J Geophys Res 116:B07306. doi:10.1029/2010JB007945

O’Hara K, Mizoguchi K, Shimamoto T, Hower JC (2006) Experimental frictional heating of coal gouge at seismic slip rates: 
evidence for devolatilization and thermal pressurization of gouge fluids. Tectonophysics 424:109-118

Obara K (2002) Nonvolcanic deep tremor associated with subduction in southwest Japan. Science 296:1679-1681

Ohtomo Y, Shimamoto T (1994) Significance of thermal fracturing in the generation of fault gouge during rapid fault motion: an experimental verification. J Tecton Res Group Jpn 39:135-144

Oohashi K, Hirose T, Shimamoto T (2011) Shear-induced graphitization of materials during seismic fault motion: Experiments and possible implications for fault mechanics. J Struct Geol 33:1122-1134

Oohashi K, Hirose T, Shimamoto T (2013) Graphite as a lubricating agent in fault zones: an insight from low- to high-velocity friction experiments on a mixed graphite-quartz gouge. J Geophys Res 118:2067-2084. doi:10.1002/jgrb.50175

Oohashi K, Han R, Hirose T, Shimamoto T, Omura K, Matsuda T (2014) Carbon-forming reactions under reducing atmosphere during seismic fault slip. Geology 42:787-790

Reches Z, Lockner DA (2010) Fault weakening and earthquake instability by powder lubrication. Nature 467:452-455

Ree J-H, Ando J, Han R, Shimamoto T (2014) Coseismic microstructures of experimental fault zones in Carrara marble. J Struct Geol 66:75-83

Ruina A (1983) Slip instability and state variable friction laws. J Geophys Res 88:10359-10370

Saito T, Ujiie K, Tsutsumi A, Kameda J, Shibazaki B (2013) Geological and frictional aspects of very-low-frequency earthquakes in an accretionary prism. Geophys Res Lett 40:703-708

Sassa K, Fukuoka H, Wang G, Wang F (2007) Undrained stresscontrolled dynamic-loading ring-shear test to simulate initiation and post-failure motion of landslides. In: Sassa K, Fukuoka H, Wang F, Wang G (eds) Progress in landslide science. Springer, New York, pp 82-98

Sato K, Kumagai H, Hirose T, Tamura H, Mizoguchi K, Shimamoto $\mathrm{T}$ (2009) Experimental study for noble gas release and exchange under high-speed frictional melting. Chem Geol 266:96-103

Sawai M, Shimamoto T, Togo T (2012) Reduction in BET surface area of Nojima fault gouge with seismic slip and its implication for the fracture energy of earthquakes. J Struct Geol 38:117-138

Senda T, Drennan J, McPherson R (1995) Sliding wear of oxide ceramics at elevated temperature. $\mathrm{J}$ Am Ceram Soc 78:3018-3024

Shelly DR (2009) Possible deep fault slip preceding the 2004 Parkfield earthquake, inferred from detailed observations of tectonic tremor. Geophys Res Lett 36:L17318. doi:10.1029/ 2009GL039589

Shimamoto T (1986) Transition between frictional slip and ductile flow for halite shear zones at room temperature. Science 231:711-714

Shimamoto T, Hirose T (2006) Reproducing low to high-velocity fault motion in fluid-rich environments: an experimental challenge and preliminary results. European Geoscience Union, General Assembly, Vienna, EGU06-A-09077

Shimamoto T, Togo T (2012) Earthquakes in the lab. Science 338:54-55

Shimamoto T, Tsutsumi A (1994) A new rotary-shear high-speed frictional testing machine: its basic design and scope of research. J Tecton Res Group Jpn 39:65-78. (in Japanese with English abstract)

Smith SAF, Di Toro G, Kim S, Ree J-H, Nielsen S, Billi A, Spiess R (2013) Coseismic recrystallization during shallow earthquake slip. Geology 41:63-66

Sone H, Shimamoto T (2009) Frictional resistance of faults during accelerating and decelerating earthquake slip. Nat Geosci 2:705-708
Spray JG (1987) Artificial generation of pseudotachylyte using friction welding apparatus: simulation of melting on a fault plane. J Struct Geol 9:49-60

Spray JG (1988) Generation and crystallization of an amphibolite shear melt: an investigation using radial friction welding apparatus. Contrib Miner Pet 99:464-475

Spray JG (1993) Viscosity determinations of some frictionally generated silicate melts: implications for fault zone rheology at thigh strain rates. J Geophys Res 98:8053-8068

Spray JG (1995) Pseudotachylyte controversy: fact or friction? Geology 23:1119-1122

Spray JG (2005) Evidence for melt lubrication during large earthquakes. Geophys Res Lett 32:L07301. doi:10.1029/2004GL022293

Spray JG (2010) Frictional melting processes in planetary materials: from hypervelocity impact to earthquakes. Annu Rev Earth Planet Sci 38:221-254

Tanikawa W, Shimamoto T (2009) Frictional and transport properties of the Chelungpu fault from shallow borehole data and their correlation with seismic behavior during the 1999 Chi-Chi earthquake. J Geophys Res 114:B01402. doi:10.1029/ 2008JB005750

Tanikawa W, Sakaguchi M, Tadai O, Hirose T (2010) Influence of fault slip rate on shear-induced permeability. J Geophys Res 115:B07412. doi:10.1029/2009JB007013

Tanikawa W, Mukoyoshi H, Tadai O (2012) Experimental investigation of the influence of slip velocity and temperature on permeability during and after high-velocity fault slip. J Struct Geol 38:90-101

Tanikawa W, Tadai O, Mukoyoshi H (2014) Permeability changes in simulated granite faults during and after frictional sliding. Geofluids (in press). doi:10.1111/gfl.12092

Tisato N, Di Toro G, De Rossi N, Quaresimin M, Candela T (2012) Experimental investigation of flash weakening in limestone. J Struct Geol 38:183-199

Togo T, Shimamoto T (2012) Energy partition for grain crushing in quartz gouge during subseismic to seismic fault motion: an experimental study. J Struct Geol 38:139-155

Togo T, Shimamoto T, Ma S, Hirose T (2011) High-velocity frictional behavior of Longmenshan fault gouge from Hongkou outcrop and its implications for dynamic weakening of fault during the 2008 Wenchuan earthquake. Earthq Sci 24:267-281

Togo T, Shimamoto T, Dong J-J, Lee C-T, Yang C-M (2014) Triggering and runaway processes of catastrophic Tsaoling landslide induced by the 1999 Taiwan Chi-Chi earthquake, as revealed by high-velocity friction experiments. Geophys Res Lett 41:1907-1915. doi:10.1002/2013GL05916

Tsutsumi A (1999) Size distribution of clasts in experimentally produced pseudotachylytes. J Struct Geol 21:305-312

Tsutsumi A, Shimamoto T (1996) Frictional properties of monzodiorite and gabbro during seismogenic fault motion. J Geol Soc Jpn 102:240-248

Tsutsumi A, Shimamoto T (1997a) High-velocity frictional properties of gabbro. Geophys Res Lett 24:699-702

Tsutsumi A, Shimamoto T (1997b) Temperature measurements along simulated faults during seismic fault motion. In: Proceedings of the 30th International Geological Congress, vol 5. VSP Press, Utrecht, pp 223-232

Tsutsumi A, Fabbri O, Karpoff AM, Ujiie K (2011) Friction velocity dependence of clay-rich fault material along a megasplay fault in the Nankai subduction zone at intermediate to high velocities. Geophys Res Lett 38:L19301. doi:10.1029/2011GL049314

Tullis TE, Weeks JD (1986) Constitutive behavior and stability of frictional sliding of granite. Pure Appl Geophys 124:383-414

Ujiie K, Tsutsumi A (2010) High-velocity frictional properties of clay-rich fault gouge in a megasplay fault zone, Nankai 
subduction zone. Geophys Res Lett 37:L24310. doi:10.1029/ 2010GL046002

Ujiie K, Tsutsumi A, Fialko Y, Yamaguchi H (2009) Experimental investigation of frictional melting of argillite at high slip rates: implications for seismic slip in subduction-accretion complexes. J Geophys Res 114:B04308. doi:10.1029/2008JB006165

Ujiie K, Tsutsumi A, Kameda J (2011) Reproduction of thermal pressurization and fluidization of clay-rich fault gouges by highvelocity friction experiments and implications for seismic slip in natural faults. J Geol Soc Lond 359:267-285

Ujiie K, Tanaka H, Saito T, Tsutsumi A, Mori JJ, Kameda J, Brodsky EE, Chester FM, Eguchi N, Toczko S, Expedition 343 and 343T Scientists (2013) Low coseismic shear stress on the Tohoku-oki megathrust determined from laboratory experiments. Science 342:1211-1214

Violay M, Nielsen S, Spagnuolo E, Cinti D, Di Toro G, Di Stefano G (2013) Pore fluid in experimental calcite-bearing faults: abrupt weakening and geochemical signature of co-seismic processes. Earth Planet Sci Lett 361:74-84
Violay M, Nielsen S, Gibert B, Spagnuolo E, Cavallo A, Azais P, Vinciguerra S, Di Toro G (2014) Effect of water on the frictional behavior of cohesive rocks during earthquakes. Geology 42:27-30

Yao L, Ma S, Shimamoto T, Togo T (2013a) Structures and highvelocity frictional properties of the Pingxi fault zone in the Longmenshan fault system, Sichuan, China, activated during the 2008 Wenchuan earthquake. Tectonophysics 599:135-156

Yao L, Shimamoto T, Ma S, Han R, Mizoguchi K (2013b) Rapid postseismic strength recovery of Pingxi fault gouge from the Longmenshan fault system: experiments and implications for the mechanisms of high-velocity weakening of faults. J Geophys Res 118:4547-4563. doi:10.1002/jgrb.50308

Yuan F, Prakash V (2008) Slip weakening in rocks and analog materials at co-seismic slip rates. J Mech Phys Solids 56: $542-560$ 